Review Article

\title{
Status of Organometallics and Catalysis Research in India: $N$ Heterocyclic Carbene (NHC) Ligands for Organometallic Catalysis
}

\author{
CHITRAKAR RAVI ${ }^{1}$, PRAGATI PANDEY ${ }^{1}$ and JITENDRA K BERA ${ }^{1, *}$ \\ 1Department of Chemistry and Centre for Environment Science and Engineering, Indian Institute of \\ Technology Kanpur, Kanpur 208 016, India
}

(Received on 03 March 2019; Revised on 25 May 2019; Accepted on 05 June 2019)

\begin{abstract}
The core activities in the field of organometallic chemistry and catalysis research in India are summarized in this article. It aims to portray the depth and diversity of the chemistry led by different research groups across the country. Selected works on the chemistry of metal-NHC compounds are highlighted.
\end{abstract}

Keywords: Organometallics; Catalysis; N-heterocyclic Carbenes (NHC); Metal-catalyzed Transformations

\section{Background}

Organometallics is the chemistry of metal-carbon bonds. The widespread interest on organometallic compounds stems largely from their intriguing structure-bonding relationships and vast applications in organic transformations. Organometallic chemistry plays a prominent role for the synthesis of fine chemicals, natural products, pharmaceuticals, agricultural products polymers and other useful materials. In recent years, sustainable processes and products are developed utilizing new generation metalbased catalytic systems. The relevance of organometallic catalysis is evident in renewable energy research. The 2005 (Casey, 2005; Chauvin, 2006) and 2010 (Nagendrappa and Kumar, 2011; Croft, 2010) Nobel prizes in chemistry are the recognition of the immense and continued impact of organometallics in chemical synthesis. The aim of this article is to present a bird's-eye view of contemporary organometallic chemistry and catalysis research in India. A comprehensive coverage is impractical within the scope of this article. Rather, it highlights the core activities of different research groups, followed by a focused and short description of the chemistry of metal-N-heterocyclic carbene (M-NHC) compounds - a self-serving choice. Efforts are made to cover significant activities that fit within the broader definition of organometallics. Any inadvertent omission, as it may well be, is regretted.

\section{Metal Salts in Catalysis}

There have been sustained activities on the direct use of metal salts as catalysts for a wide range of organic transformation reactions. Chandrasekaran group (IISc) explored the chemistry of $\mathrm{MoS}_{4}{ }^{2-}$ and $\mathrm{WSe}_{4}{ }^{2-}$ as versatile sulfur and selenium transfer reagents, respectively, to access functionalized disulfides, diselenides, selenoamides, selenoureas, and cyclicselenide derivatives (Sureshkumar et al., 2012; Suresh et al., 2005; Devarajulu et al., 2010; Devarajulu et al., 2007a; Devarajulu et al., 2007b). At IITK, Iqbal group research focused on developing synthetic methodologies involving cobalt-catalyzed functional group transformations for applications in synthetic chemistry (Iqbal et al., 1994; Bhatia et al., 1993; Punniyamurthy et al., 1993; Iqbal et al., 1991). Periasamy group (UH) demonstrated carbonylation of organic compounds using metal carbonyls (Beesu and Periasamy, 2011; Beesu and Periasamy, 2012; Periasamy et al., 2008). $\mathrm{Fe}(\mathrm{CO})_{5}$ was employed for the carbonylation of alkynes to obtain cyclobutenediones and anhydrides (Periasamy et al., 2004). In addition, they developed new synthetic methodology involving $\mathrm{TiCl}_{4} / \mathrm{R}_{3} \mathrm{~N}$ reagent systems

*Author for Correspondence: E-mail:jbera@iitk.ac.in 
(Periasamy, 2002; Bharathi and Periasamy, 1999; Bharathi and Periasamy, 2000; Periasamy et al., 2010; Karunakar and Periasamy, 2006). Kotha group (IITB) exploited various ruthenium catalyzed metathesis reactions as key steps to access ring annulated products (Kotha and Gunta, 2017; Kotha et al., 2015; Kotha et al., 2011; Kotha and Chavan, 2010; Kotha and Khedkhar, 2009; Kotha et al., 2009). Further, they exploited Suzuki-Miyaura cross-coupling strategy to access diverse polycyclic aromatics (Kotha and Ghosh, 2004; Kotha and Mandal, 2006; Kotha and Mandal, 2009; Kotha et al., 2007; Kotha et al., 2002). M. Lakshmi Kantam from IICT has exploited metal nanoparticles on different solid supports for a wide variety of organic transformations (Layek et al., 2012; Chakravarti et al., 2011; Kantam et al., 2013; Arundhathi et al., 2013; Kantam et al., 2009). Ranu group (IACS) used metal nanoparticles as catalysts for a variety of organic transformation reactions, in particular, $\mathrm{Pd}$ and $\mathrm{Fe}$ nanoparticles for direct $\mathrm{C}-\mathrm{H}$ functionalization (Saha et al., 2010; Panja et al., 2017; Chatterjee et al., 2014; Kundu, et al., 2013) and reduction reactions (Panja et al., 2017; Dey et al., 2012; Saha and Ranu, 2008).

\section{Organometallic Chemistry}

These activities had a thick organic chemistry flavor. Other research groups have pursued classical organometallic chemistry research that includes the synthesis of organometallic compounds, their reactivity studies and potential use in catalysis. S S Krishnamurthy (IISc) group designed and developed an array of P-N and P-N-P based ligands. Palladiumallyl, ruthenium-hydride and carbonyl cluster compounds supported by those ligands were synthesized and exploited in catalytic coupling and transfer hydrogenation reactions (Reddy et al., 1992; Maji et al., 2011; Mandal et al., 2003; Venkatakrishnan, et al., 2006; Venkatakrishnan, et al., 2007; Mandal et al., 2006). Chandrasekhar group (IITK) studied the organometallic chemistry of main group elements (Chandrasekhar et al., 2009a; Chandrasekhar et al., 2009b). Significant advances were made in the chemistry of organostannoxane and organotelluroxane compounds. Carboxylates, phosphate and sulphonates supported organotin molecular assemblies were synthesized and structurally characterized (Chandrasekhar et al., 2007; Chandrasekhar et al., 2005). Organostann- oxane supported palladium nanoparticles were employed for the efficient cross-coupling reactions (Heck and Suzuki) (Chandrasekhar et al., 2009; Chandrasekhar et al., 2011). Bhaduri at Reliance Industries studied platinum and ruthenium carbonyl cluster complexes and exploited inorganic-oxides supported metal carbonyl catalysts for hydrogenation reactions (Bhaduri et al., 1998; Bhaduri et al., 1983; Basu et al., 1986; Bhaduri et al., 2001; Paul et al., 2003). They also developed technologies for the industrial scale manufacture of polypropylene utilizing supported or modified Ziegler-Natta type of catalysts (Gnanakumar et al., 2011; Bhaduri et al., 2006; Thushara et al., 2012). Singh group (IITB) works on the organoselenium and organotellurium compounds (Manjare et al., 2012; Kumar et al., 1990; Panda et al., 1990). The coordination behavior of these compounds with $\mathrm{Pd}(\mathrm{II})$ has been studied (Chakraborty et al., 2011a; Chakraborty et al., 2011b) and the catalytic utility of these complexes are evaluated for cross-coupling reactions (Ghavale et al., 2015; Chakraborty et al., 2011a). Samuelson (IISc) group examines anti-cancer activities of half-sandwich metal complexes with heterocyclic ancillary ligands (Mitra et al., 2012; Mitra et al., 2014). Besides metalcatalyzed transformation reactions, (Dinda et al., 2010; Kumar et al., 2011) his group undertakes electronic structure calculations to gain insight on bonding and energetics of organometallic compounds (Bera et al., 1999; Dindar et al., 2012). E D Jemmis (UH/IISc/IISER-TVM) (Jemmis et al., 2002; Jemmis et al., 2003; Kiran et al., 2002; Roy et al., 2014; Mondal et al., 2018) and R B Sunoj (IITB) (Jindal et al., 2014; Reddi et al., 2019; Kumarasamy et al., 2017; Bhaskararao and Sunoj, 2015) offer theoretical perspectives on the structures, bonding and reactivities of organometallic compounds. Mathur (IITB) explored the cluster chemistry involving chalcogenbridged mixed-metal carbonyl clusters (Datta et al., 1994; Mathur et al., 1994; Mathur et al., 2000; Mathur et al., 2000; Mathur et al., 2002; Klose et al., 2003) and their acetylenic derivatives (Mathur et al., 1995; Mathur et al., 1993; Mathur et al., 1996; Mathur et al., 1995). Gupta group (IITK) examined the structure-property relationship of organo-cobalt and vitamin B12 model compounds (Gupta et al., 2011; Dutta et al., 2011; Bhuyan et al., 2008; Mandal and Gupta, 2007). The reactivity of the $\mathrm{Co}-\mathrm{C}$ bond was examined by the reactions of organocobaloximes with 
molecular oxygen and $\mathrm{Br}_{2}$ (Kumar and Gupta, 2011; Mandal et al., 2007; Kumar et al., 2011; Dutta et al., 2012). Elias (IITD) has developed cobalt and iron sandwich compounds bearing tetraphenylcyclobutadiene and cyclopentadiene derivatives (Kumar et al., 2016). Several donor groups are attached on the $\mathrm{Cp}$ ring and their metal complexes are synthesized (Hazra et al., 2017; Singh et al., 2016). Palladacycles constructed by chemical modification of the $\mathrm{Cp}$ ring were utilized for organic transformation reactions (Singh et al., 2015; Singh and Elias, 2011; Singh et al., 2014). His group earlier pursued organometallic reactions on moieties derived from cyclophosphazene cores (Elias et al., 2011; Kumar et al., 2014; Kumar et al., 2008; Keshav et al., 2010; Kumar et al., 2011). Lahiri (IITB) has employed well known Ru based catalysts for alcohol dehydrogenation, amide synthesis from primary and secondary amines and epoxidation reactions (Ray et al., 2018; Ray et al., 2014; Chowdhury et al., 2011). Iron salts are also used for oxidation and nitrosation of terminal alkenes (Chowdhury et al., 2012a; Chowdhury et al., 2012b; Ray et al., 2013). Jagirdar group (IISc) is engaged in examining heterocyclic X$\mathrm{H}$ bond activation at highly electrophilic metal center (Nagaraja et al., 2007; Mala et al., 2017; Mala et al., 2018; Ramaraj et al., 2016). Their work has provided valuable insight on the $\mathrm{H}$-atom exchange process between the $\eta^{2}-\mathrm{H}_{2}$ and hydride ligands on the metal. His group has also developed a protocol for the synthesis of metal and bimetal alloy nanoparticles employing amine-boranes with appropriate metal salts. The use of amine-borane serves dual purposes - to reduce the metal ions to its elemental form and the generated BNHx polymer acts as stabilizing agent. Dissolution of the capping polymer in water afforded mesoporous metal nanosponges which are conveniently used for a variety of reduction reactions under mild conditions (Kalidindi et al., 2011; Sanyal and Jagirdar, 2012; Kalidindi and Jagirdar, 2012; Ghosh and Jagirdar, 2018). Roy group (IICT/IITKGP/IIT Bhubaneswar) developed heterobimetallic chemistry for catalytic organic transformations (Das et al., 2015; Roy and Roy, 2010; Das et al., 2012). Notably, transition metal-tin (TM-Sn) systems are devised for allylation, propargylation, allenylation, selenylation, benzylation reactions (Choudhury et al., 2005; Podder et al., 2007a; Podder et al., 2007b; Kundu and Roy, 2007). A. K. Singh group (IITD) has exploited Pd,
$\mathrm{Ru}$, Ir compounds with organochalcogen ligands for cross-coupling, oxidation and transfer hydrogenation reactions (Bhaskar et al., 2018; Prakash et al., 2013; Dubey et al., 2018; Saleem et al., 2013). Pandey at BHU uses half-sandwich Ru arene complexes for a variety of purposes (Kumar et al., 2014; Singh et al., 2014). Singh expands the similar chemistry at IITI (Dwivedi et al., 2018; Awasthi et al., 2018). Ghosh at IITM has combined organometallic fragments with borane constructs (De et al., 2018; Anju et al., 2014; Saha et al., 2017). Anantharaman (IITK) studies metal-NHC compounds and their catalytic activity towards cross-coupling reactions (Karthik et al., 2014; Bhat et al., 2019; Karthik et al., 2013).

\section{Organometallic Catalysis}

Rao (IITK) explores palladium catalyzed crosscoupling reactions for organic synthesis. Stable triarylbismuths are effectively used as aryl transfer reagents under palladium-catalyzed conditions for a wide variety of $\mathrm{C}-\mathrm{C}$ bond forming reactions (Shimada and Rao, 2012; Rao et al., 2010a; Rao et al., 2010b; Rao et al., 2008). Sekar (IITM) group research emphasizes on metal nanocatalysts (Savitha et al., 2016a; Savitha et al., 2016b; Surya et al., 2016; Ganapathy et al., 2014; Sharma et al., 2017). Further, they have studied metal-catalyzed reduction of $\alpha$-keto amides and their functionalization (Mamillapalli and Sekar, 2015a; Mamillapalli and Sekar, 2014; Mamillapalli and Sekar, 2015b; Kotha et al., 2014; Muthukumar and Sekar, 2017; Muthukumar et al., 2018). Punniyamurthy (IITG) focuses on the transition-metal catalyzed stereoselective carboncarbon and carbon-heteroatom bond formation (Talukdar et al., 2019; Banerjee et al., 2019; Satheesh et al., 2018; Mahesh et al., 2017; Mahesh et al., 2016; Sengoden et al., 2017; Sengoden and Punniyamurthy, 2013). Hotha (IISER Pune) group employs gold catalysts for the synthesis of glycosides and furanosides respectively (Hotha and Kashyap, 2006; Kayastha and Hotha, 2012; Thadke et al., 2013; Vidadala et al., 2011; Sureshkumar and Hotha, 2008). The metal-catalyzed $\mathrm{C}-\mathrm{H}$ bond activation and functionalization is an important area of research in chemical synthesis. Several groups are independently leading this activity- notable names are Maiti (Achar et al., 2018; Maji et al., 2018; Deb et al., 2017), Jeganmohan (Ramesh and Jeganmohan, 2017; Reddy and Jeganmohan, 2017; Manikandan et al., 2016), 
Anbarasan (Reddy et al., 2017; Yadagiri et al., 2016; Yadagiri and Anbarasan, 2015), Sundararaju (Kalsi et al., 2018; Barsu et al., 2017; Sen et al., 2016), and Baidya (Mandal et al., 2017; Dana et al., 2018a; Dana et al., 2018b).

Chattopadhyay group (CBMR, Lucknow) engineered new catalytic systems integrating noncovalent interactions on transition metal complexes to generate novel concepts and hypotheses in $\mathrm{C}-\mathrm{H}$ activation chemistry. Moreover, they have developed series of new denitrogenative annulation strategies employing organometallic complexes for the construction of diverse nitrogen heterocycles (Bisht et al., 2018; Smith III et al., 2018; Bisht and Chattopadhyay, 2016; Hoque et al., 2017). Gunanathan (NISER) group studies ruthenium catalyzed deuteration of organic compounds using $\mathrm{D}_{2} \mathrm{O}$ to labelled products (Chatterjee et al., 2016; Krishnakumar and Gunanathan, 2018; Chatterjee and Gunanathan, 2016; Chatterjee and Gunanathan, 2015; Thiyagarajan and Gunanathan, 2019). Balaraman group (IISER-Tirupati) efforts lie in the domain of catalytic hydrogenation and dehydrogenation reactions (Midya et al., 2015; Sahoo et al., 2017; Sahoo et al., 2018; Jaiswal et al., 2017; Nandakumar et al., 2015). Chikkali group (CSIR-NCL) uses metal catalysts bearing phosphorus ligands featuring supramolecular binding property for hydrophosphination, hydrogenation, hydroformylation, polymerization reactions (Koshti et al., 2014; Koshti et al., 2015; Pandey and Chikkali, 2015; Pandey et al., 2018; Mote et al., 2017). Biplab group (IISERK) is developing new synthetic methodology using manganese catalyst to construct new $\mathrm{C}-\mathrm{C}$ bonds by alcohols activation (Barman et al., 2018a; Maji and Barman, 2017; Barman et al., 2018b; Jana et al., 2018). Kundu (IITK) group has exploited alcohol as an alkylating agent to construct new C-C and C-N bonds for organic synthesis (Shee et al., 2018; Paul et al., 2018; Maji et al., 2018; Chakrabarti et al., 2017).

\section{Heterogeneous Catalysis}

Although most activities in organometallic catalysis are confined under homogenous conditions, there is a vibrant community who work on heterogeneous catalysis. Prof. B M Choudary from IICT, Hyderabad is the pioneer utilizing layered double-hydroxides, copper apatite, nanocrystalline $\mathrm{MgO}, \mathrm{OsO}_{4}$ incorporated in resins, for a range of reactions such as $\mathrm{C}-\mathrm{H}$ activation, $\mathrm{N}$-arylation of hetreocycles, Claisen-Schmidt condensation, asymmetric epoxidation and dihydroxylation of olefin (Choudary et al., 2005; Choudary et al., 2004; Choudary et al., 2002; Choudary et al., 2001). P. Selvam from IITM has synthesized several heterogeneous catalysts based on mesoporous silica (MCM-41) and their aluminate derivatives. These catalysts are evaluated for selective oxidation, hydrogenation, wet air oxidation of aniline, reductive cleavage of azo compounds (Selvam et al., 2011; Mohapatra et al., 2002; Gomes et al., 2005; Sonavane et al., 2003). S B Umbarkar from NCL, Pune exploited in situ generated molybdenum oxo-peroxo complexes as recyclable catalysts for oxidation reactions (Biradar et al., 2008; Chandgude et al., 2012; Nguyen et al., 2012; Chandra et al., 2013). In recent time, V. Polshettiwar group from TIFR, Mumbai developed dendritic fibrous nano-silica (DFNS) based nanocatalysts, such as TaH supported on silica, single atoms and nanoparticles of metal supported on amine and polyamine functionalized DFNS, for various range of catalytic transformations and $\mathrm{CO}_{2}$ capture-conversions (Bayal et al., 2017; Polshettiwar et al., 2011; Polshettiwar et al., 2009; Polshettiwar et al., 2010; Singh and Polshettiwar, 2009).

\section{Books on Organometallic Chemistry}

The continued tradition of organometallic chemistry is reflected in the numbers of books written by Indian authors. Prof. R C Mehrotra offered an introductory account of organometallic chemistry (Mehrotra, 2000). V Chandrasekhar has authored a book on Inorganic and Organometallic polymers (Chandrasekhar, 2005). Anil Elias and B D Gupta (Gupta and Elias, 2010; 2013) have written a modern book on organometallics that has become an essential handbook for students and teachers as well. Anil Elias has recently introduced a well-researched book on the chemistry of the p-block elements (Elias, 2018). S. Bhaduri and D. Mukesh have written a book on homogeneous catalysis with particular emphasis on industrial applications (Bhaduri and Mukesh, 2014).

\section{Metal-N-heterocyclic Carbene Complexes}

Arduengo reported the first stable NHC (1,3diadamantylimidazole-2-ylidene) in 1991 (Scheme 1). Initially NHCs were viewed as neutral 2-e donor 


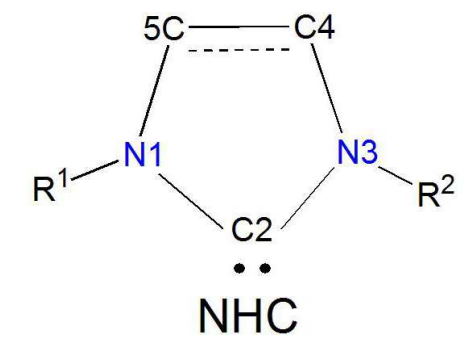

Scheme 1: Line drawing of a NHC

alternatives to phosphines and the synthesis to metalNHC compounds was considered difficult than their phosphine counterparts. However, NHCs soon found numerous applications, and prominently in organometallic catalysis. Several synthetic protocols are developed over the years to access metal-NHC compounds. It is now well recognized that NHCs offer several advantages over phosphines. The NHC features a directional $\mathrm{sp}^{2}$-type lone pair compared to non-directional $\sigma$-type orbital for phosphine. The extent of $\pi$-back-bonding is lower in metal-NHC than in metal-phosphine complexes. These factors contribute to the stability of the metal-NHC compounds imposing higher electron density on the metal center. It has direct implications on their performances in catalytic processes. The Pd-NHC catalysts are in general more active and offer better turnover values for cross-coupling reactions than related phosphine-based catalysts. The evolution of Grubbs olefin metathesis catalysts is another example of the superiority of NHC ligands over phosphines.

The phosphine ligands played an important role in the early development of organometallic chemistry and catalysis. The footprint of Indian chemists in that era had been rather limited. In recent times, metalcatalyzed reactions involving metal-NHC compounds are the major topics of catalysis reserach and Indian chemists are making a sizable contribution to this field. We focus on research from selected groups engaged in exploring the chemistry of metal-NHC compounds.

\section{Selected Works on the M-NHC Chemistry in India}

Sarkar group at NCL Pune worked on the chemistry of metal-carbene complexes. A variety of reactions involving Fischer carbene complexes were studied including alkylation (Amin and Sarkar, 1995) and annulation, (Mathur et al., 1998) regioselective 1,3dipolar addition of organic azides (Chakraborty et al.,
2010) and rearrangement to ketone (Nandi et al., 1992). Thermal rearrangement of aryl((arylmethyl) oxy)-carbene complexes of $\mathrm{Cr}$ and $\mathrm{W}$ afforded the corresponding ketones (Scheme 2). The

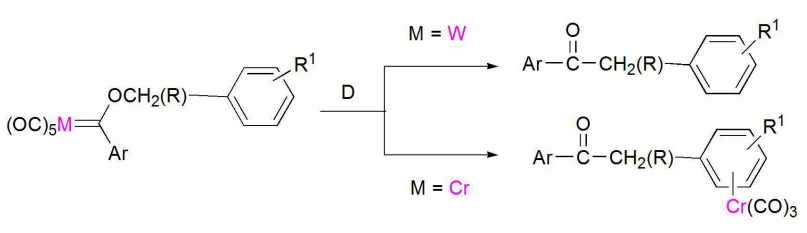

Scheme 2: Rearrangement of Fischer carbene complexes to ketones

rearrangement is general and applicable for aryl(allyloxy)carbene complexes as well. It was demonstrated that electronic tuning on the carbene carbon dictates the reactivity of the complexes. (Sathe et al., 1996)

Sarkar exploited suitably modified Fischer carbene complexes for the reduction of Au salts and stabilization of nanoparticles (Samanta et al., 2006). Hydrophilic Fischer carbene complexes are used as organometallic bio-markers (Samanta et al., 2005). A ferrocene-analog of Grubbs catalyst was developed which show efficient RCM reactions (Scheme 3) (Maishal and Sarkar, 2002).

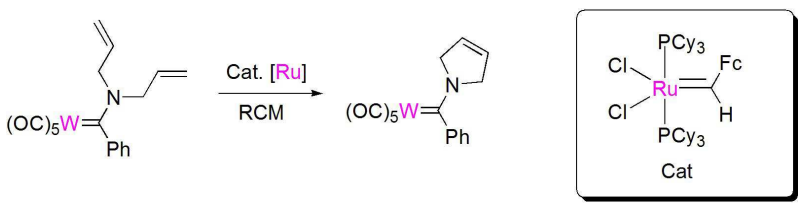

Scheme 3: An air-stable, reusable, ferrocene-analog of Grubbs catalyst

Ghosh at IITB initiated the chemistry of NHC based metal complexes, (Ramasamy and Ghosh, 2016; John and Ghosh 2010) focusing on exploring the potential of these compounds in biomedical applications, with a particular emphasis on developing $\mathrm{Pd}-\mathrm{NHC}$ complexes for anticancer studies (Scheme 4a), (Kumar et.al., 2017; Ray et al., 2007a; Kumar et.al., 2018) and also in catalytic applications. On the homogeneous catalysis front, Ghosh's group have demonstrated the utility of these complexes for simple Pd-mediated $\mathrm{C}-\mathrm{C}$ cross-coupling reactions like the Suzuki, (Ray et al., 2007b) Sonogashira (Scheme 4b) 
(John et.al., 2009) and the Hiyama couplings (Modak et.al., 2015). Ghosh's group has successfully developed the more challenging bifunctional catalysis on NHC ligand platforms using nickel complexes for the chiral (Rao et al., 2015) and achiral (Samantaray et al., 2009; Ray et al., 2009) variants of the basefree Michael addition reactions (Scheme 4c). Further, his group also reported Fe-NHC complexes for asymmetric Michael addition reactions (Prakasham et al., 2018). They pursued applications of these complexes in industrially important and environmentally relevant atom-economic reactions like the hydroamination of activated olefins (Scheme 4d) (Kumar et al., 2017; Dash et al., 2010a) and the hydroamination of alkynes (Scheme 4e) (Katari et al., 2012; Dash et al., 2010b). Ghosh successfully performed silylation reactions in the form of hydrosilylation of carbonyl compounds using iron complexes (Scheme 4f) (Kumar et al., 2014) and reported the catalytic utility of inert coinage metals like silver and gold in polymerization reactions for producing environmentally benign polylactide polymers using Ring Opening Polymerization of L-lactides (Scheme 4g) (Samantaray et al., 2006; Ray et al.,
2006). In the domain of asymmetric catalysis, Ghosh's group has reported rhodium and iridium based precatalysts for the transfer hydrogenation of ketones (Scheme 4h) (Ramasamy et al., 2017). Overall, Ghosh's group work represents the expansion of the application space, both biomedical and catalytic, of NHC based metal complexes using variation in carbene ligands and their well-defined metal complexes along with obtaining detailed mechanistic insights for further improvements of the property of interest.

Mandal at IISER Kolkata developed the chemistry of mesoionic carbene (MIC) which is also known as abnormal N-heterocyclic carbene $(a \mathrm{NHC})$ where $\mathrm{C} 2$-position of imidazole ring is blocked with a phenyl group. By virtue of its strong nucleophilic nature (Thakur et al., 2016; Sau et al., 2016; Sau et al., 2019; Hota et al., 2018), a variety of transition metal complexes were prepared (Scheme 5). For example, Mandal and co-workers prepared halobridged $\mathrm{C}-\mathrm{H}$ activated palladium dimers (Scheme 5(a)) (Hota et al., 2015; Hota et al., 2017), which are active catalysts for the Suzuki-Miyaura cross-coupling of a number

\section{Ghosh's Work}

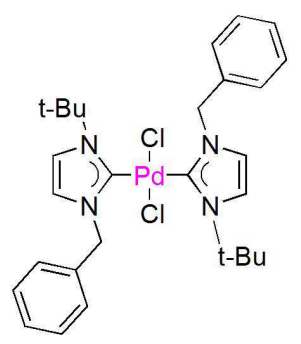

(a)

Anticancer application

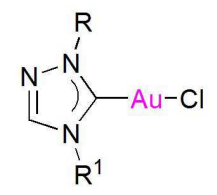

$\mathrm{R}=\mathrm{CH}_{2} \mathrm{CO}^{t} \mathrm{Bu}, \mathrm{R}^{1}=\mathrm{CH}_{2} \mathrm{Ph}$ $\mathrm{R}=\mathrm{CH}_{2} \mathrm{CONH}^{t} \mathrm{Bu}, \mathrm{R}^{1}=\mathrm{CH}_{2} \mathrm{Ph}$

(e)

Hydroamination of alkynes

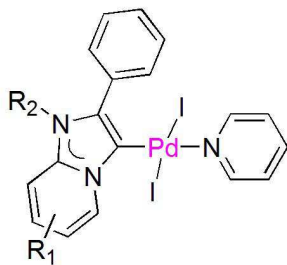

(b)

Sonogashira coupling

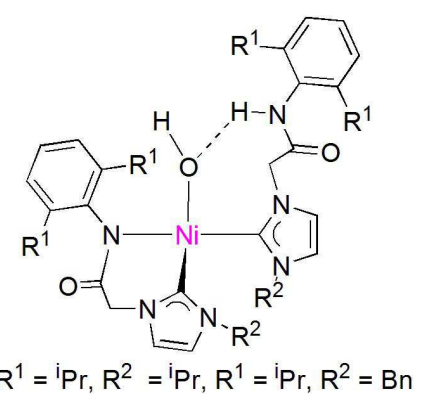

(c)

Michael addition reactions

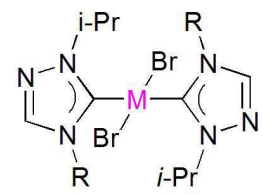

$\mathrm{M}=\mathrm{Ni}$ or $\mathrm{Pd}$

$\mathrm{R}=$ Ethyl, allyl

(d)

Hydroamination of activated olefins

Scheme 4: Catalysts developed in Ghosh laboratory and catalytic activities 
of aryl chlorides at room temperature with low catalyst loading (up to $0.005 \mathrm{~mol} \%$ ) (Sau et al., 2012; Sreejyothi et al., 2018; Ahmed et al., 2017). Importantly, complex (a) remained active for 10 successive catalytic runs without any loss of its activity, confirming the robustness of the Pd- $a$ NHC bond. More recently, complex (a) was reported as an active catalyst for dehydrogenative cross-coupling using a variety of heteroarenes such as benzothiazole, benzoxazole, 2-formyl thiophene, furfural and $\mathrm{N}$ methyl benzimidazole. $\mathrm{Cu}(\mathrm{I})-\mathrm{MIC}$ complex (Scheme $\mathbf{5 b}$ ) was applied for cycloaddition of azides and alkynes at very low catalyst loadings and a wide range of triazoles in good to excellent yields were obtained (Scheme 5) (Sau et al., 2013). The MIC based iron (0) catalyst (Scheme 5c) was used for selective hydrosilylation of various aldimines and ketimines for the synthesis of corresponding amines (Bhunia et al., 2016). An aryl C-H activated nickel(II) cyclooctenyl complex (Scheme 5d) was also isolated (Vijaykumar et al., 2017). Complex (5d) catalyzes hydroheteroarylation of various olefins through $\mathrm{C}-\mathrm{H}$ bond activation, offering a highly atom-economical method for the synthesis of 1,1- or 1,2-diarylalkanes. Besides transition metal chemistry, Mandal and co-workers also prepared main-group metal complexes (5e), (5f) and (5g) (Scheme 5). (MIC)K(I) complex was utilized for the polymerization of $\mathrm{rac}$-lactide in toluene at room temperature showing $96 \%$ conversion within $2.5 \mathrm{~h}$ (Bhunia et al., 2017). (MIC)Al(III) complex (Scheme 5f) and (MIC)Zn(II) complex (Scheme 5g) also act as catalysts for the ring opening polymerization of various cyclic esters (Sen et al., 2013).

Choudhury group (IISERB) has revealed an unprecedented chemistry of Rh-NHC backbone for the synthesis of highly conjugated, cationic and annulated organic molecules (Ghorai and Choudhury, 2014; Ghorai and Choudhury, 2015; Thenarukandiyil and Choudhury, 2015; Ghorai et al., 2016; Thenarukandiyil et al., 2016a; Thenarukandiyil et al., 2016b; Dutta et al., 2019). The rhodium(III) catalyzed $\mathrm{C}-\mathrm{H}$ bond activation of aromatic, heteroaromatic and vinylic motifs was achieved by utilizing a novel conjugative action of $\mathrm{NHC}$ ligand as directing group followed by insertion of internal alkynes and subsequent annulation of various imidazolium salts (Scheme 6a-c). They also reported a series of iridium(III)-NHC complexes with varying ring size for hydride-transfer reaction (Semwal et al., 2014; Semwal et al., 2017). Based on the bite angle and yaw angle of these complexes, their electronic properties were studied for the efficient hydride donor

\section{Mandal's work}

Transition-metal catalysts of Mesoionic Carbene (MIC)

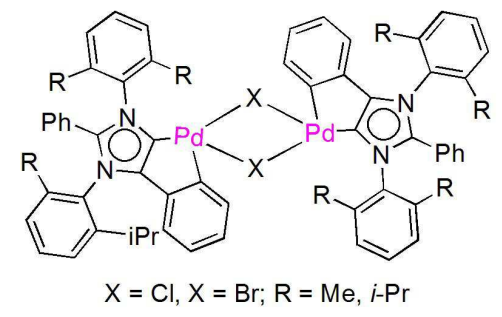

(a)

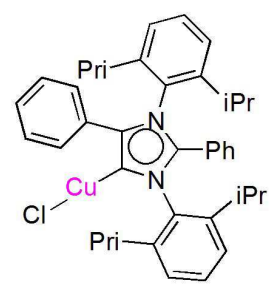

(b)

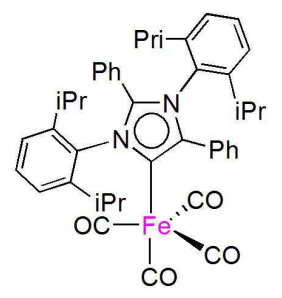

(c)

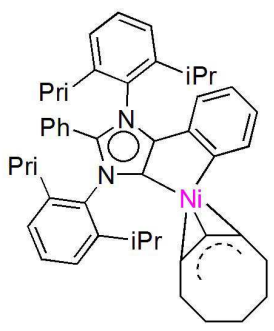

(d)

Main-group-metal catalysts of Mesoionic Carbene (MIC)

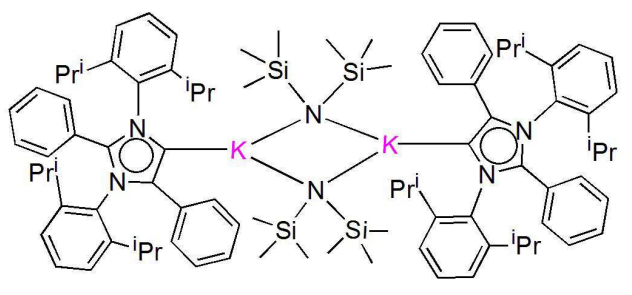

(e)

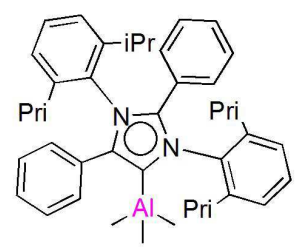

(f)

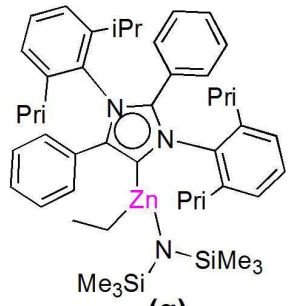

(g)

Scheme 5: Catalysts developed in Mandal laboratory 
ability to unsaturated organic molecules (Scheme 6d). Along this line, recently they developed $a$ NHC-based iridium catalyst featuring a hybrid anionic amido-type supporting ligand for $\mathrm{CO}_{2}$-conversion chemistry (Scheme 6e) (Semwal et al., 2018; Kumar et al., 2019). Further, they have introduced smartly designed benzimidazole-pyridinylidene-based NHC hybrid ligand constructed $\mathrm{Ir}$ and $\mathrm{Ru}$ complexes as a new class of 'molecular switch' to demonstrate stimuliswitchable hydrogenation/dehydrogenation catalysis for reversible hydrogen storage and delivery processes (Scheme 6f) (Semwal and Choudhury, 2016; Semwal and Choudhury, 2017). The same group has reported a series of Pd-mono and bis-imidazolylidene-NHC (Scheme 6g) and Ru-NHC-based complexes (Scheme 6h) for oxidative $\mathrm{C}-\mathrm{H}$ functionalization (acetoxylation and halogenation) of arenes and oxidative scission of alkenes and alkynes to the corresponding carbonyl compounds, respectively (Desai et al., 2015; Gupta et al., 2016; Gupta and Choudhury, 2016).

Bera group designs and develops organometallic catalysts for the conversion of earth-abundant molecules to useful chemical feedstock. Employing 'bifunctional' metal-ligand cooperation strategy, new bond activation mechanism has been devised. Utilizing water as a reagent, nitrile hydrations (Scheme 7a-b), (Daw et al., 2012; Singh et al., 2017) olefin oxygenation (Scheme 7c) (Ghatak et al., 2015) and direct conversion of alcohol to carboxylic acid (Scheme 7d) (Sarbajna et al., 2017) have been demonstrated in his laboratory. Recent research in Bera group is geared towards the development of sustainable processes and products. Alternate catalytic method is established that avoids the use of hazardous ozone generator for the selective conversion of olefins to aldehydes (Scheme 7e) (Daw et al., 2014). Alcohols are catalytically dehydrogenated followed by dehydrogenative coupling on a dimetal platform (Scheme 7f) (Saha et al., 2014). Employing bifunctional activation strategy, amines are doubly dehydrogenated to nitriles providing two molecules of dihydrogen under acceptorless and oxidant-free conditions (Scheme 7g) (Dutta et al., 2018). This recent result raises the prospect of amines as Liquid Organic Hydrogen Carrier (LOHC). New strategies are being developed for catalyst systems that would hydrogenate the dehydrogenated product nitrile back to amine using abundant biomass. Double dehydrogenation of amine under moderate conditions with an output of two molecules of hydrogen gas and off-site refueling utilizing biomass is an important step towards the goal of establishing hydrogen economy.

\section{Choudhury's Work}

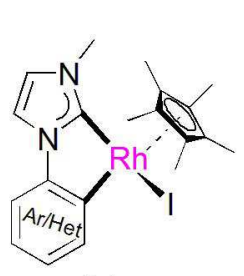

(a)

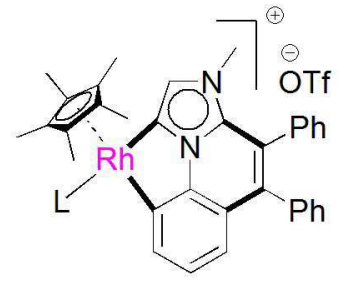

(b)

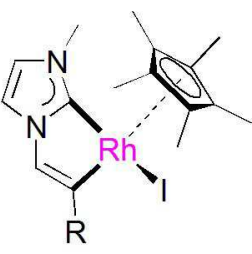

(c)

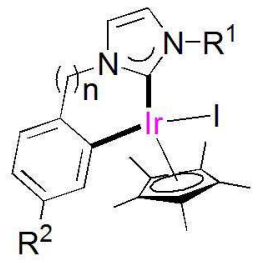

(d)

$\mathrm{C}-\mathrm{H}$ activation-annulation chemistry on $\mathrm{Rh} \mathrm{NHC}$ template

Hydride transfer catalysts

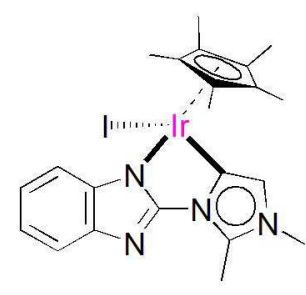

(e)

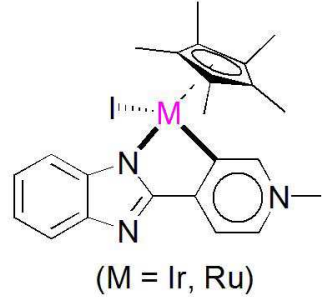

(f)

Ambient-pressure CO2-conversion

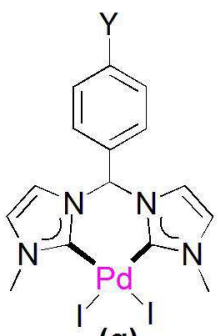

(g)

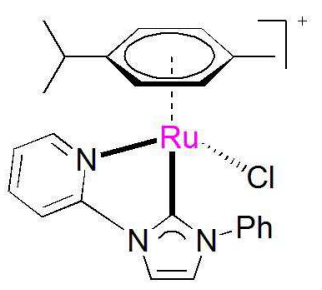

(h) $\begin{array}{ccc}\text { Molecular switch } & \text { Oxidative arene } \mathrm{C}-\mathrm{H} & \text { Alkene/alkyne oxidation } \\ \text { and switchable catalysis } & \text { functionalization catalyst } & \text { catalyst }\end{array}$

Scheme 6: Catalysts developed in Choudhury laboratory 


\section{Bera's work}

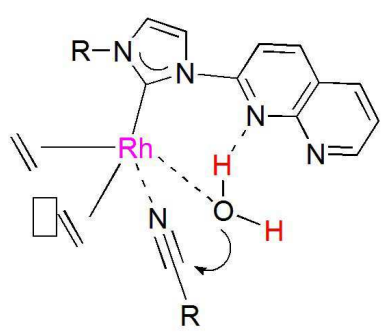

(a)

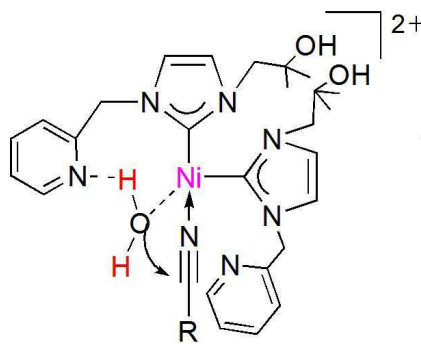

(b)

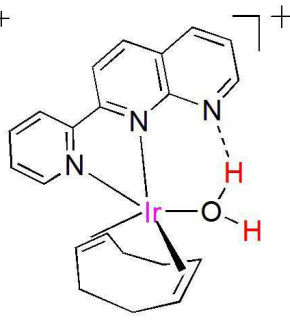

(c)

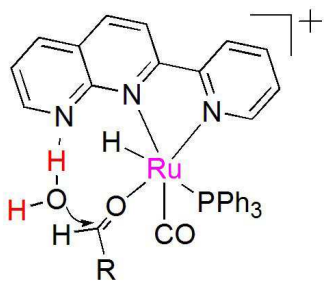

(d)

Nitrile hydration

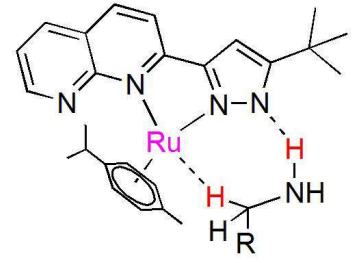

(e)

Oxidative cleavage of alkene

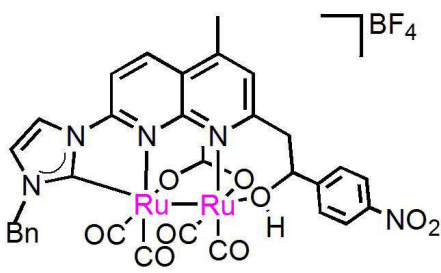

(f)

Dehydrogenative coupling

Oxygenation of olefin

Oxidation of alcohol

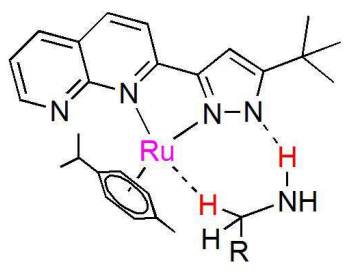

(g)

Amine dehydrogenation

Scheme 7: Bera group catalysts and their activities

Jana group at TIFR, Hyderabad demonstrated that NHC can reversibly coordinate to the $p$-block compound, diphosphene $\operatorname{Ter}^{\mathrm{Mes}} \mathrm{P}=\mathrm{PTer}{ }^{\mathrm{Mes}}$, at room temperature (Scheme 8) (Dhara et al., 2018).

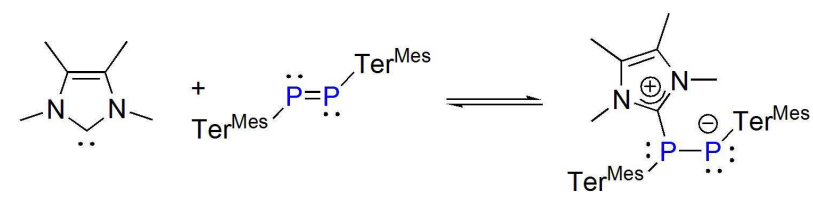

Scheme 8: Reaction of $N$-heterocyclic carbene with diphosphene

The same group further reported the abnormal addition of $\mathrm{NHC}^{\text {Dip }}$ to a conjugate acid of CAAC which leads to the adduct formation (Scheme 9)

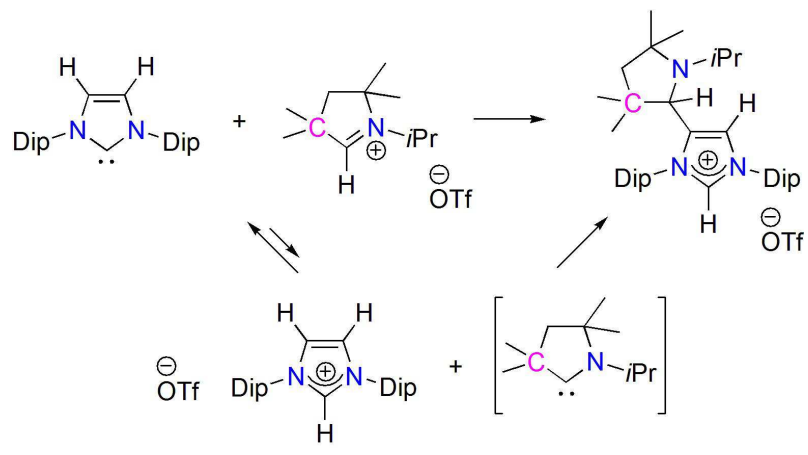

Scheme 9: "Abnormal" addition of NHC to CAAC
(Mandal et al., 2018). Mechanistic studies revealed that it proceeds through in situ formation of an imidazolium cation and $N-i \operatorname{Pr}$ substituted CAAC, followed by oxidative addition.

\section{Concluding Remarks}

It has been a challenge to capture the essence of India's organometallic chemistry and catalysis research in this concise article. The efforts have been to convey the diversity and the depth of the chemistry. Hopefully this article would allow one to assess the Indian contribution in organometallic chemistry and catalysis field. Last few years have witnessed a dramatic development in organometallic research, transitioning from classical studies on organometallic compounds to catalyst design and development for challenging molecular transformations. The infusion of young talents has made the field highly vibrant and competitive. A critical mass is reached. The future of organometallic chemistry research in India looks bright today.

\section{Acknowledgements}

I thank colleagues, far too many to mention individually, for their insights and comments on this 
article. The contributions of the organometallic research community who laid the foundation, on which the present generation continues to build up, are gratefully acknowledged. The generous support by the DAE, India for our research is much appreciated. JKB thanks the SERB, DST India for the J C Bose fellowship. C.R. thanks IITK for a post-doctoral fellowship. P.P. thanks CSIR for a fellowship.

\section{References}

Achar T K, Ramakrishna K, Pal T, Porey S, Dolui P, Biswas J P and Maiti D (2018) Regiocontrolled remote $\mathrm{C}-\mathrm{H}$ olefination of small heterocycles Chem-Eur J 24 1790617910

Ahmed J, Sau S C, Sreejyothi P, Hota P K, Vardhanapu P K, Vijaykumar G and Mandal S K (2017) Direct C-H arylation of heteroarenes with aryl chlorides by using an abnormal N Heterocyclic carbene-palladium catalyst Eur J Org Chem 2017 1004-1011

Amin S K R and Sarkar A (1995) Aqueous organometallic chemistry: Phase-transfer-catalyzed alkylation of Fischer carbene complexes Organometallics 14 547-550

Anju R S, Roy D K, Mondal B, Yuvaraj K, Arivazhagan C, Saha K, Varghese B and Ghosh S (2014) Reactivity of diruthenium and dirhodiumanalogues of pentaborane(9): Agostic versus boratranecomplexes Angew Chem Int Ed 53 2873-2877

Arundhathi R, Damodara D, Mohan K V, Kantam M L and Likhar P R (2013) Monodispersed and stable nano copper(0) from copper-aluminium hydrotalcite: importance in C-C couplings of deactivated aryl chlorides Adv Synth Catal 355 751-756

Awasthi M K, Tyagi D, Patra S, Rai R K, Mobin S M and Singh S K (2018) Ruthenium complexes for catalytic dehydrogenation of hydrazine and transfer hydrogenation reactions Chem Asian J 13 1424-1431

Banerjee S, De P B, Pradhan S, Shah T A and Punniyamurthy T (2019) $\mathrm{Ru}$ (II)-catalysed regioselective $\mathrm{C}-\mathrm{N}$ bond formation of indolines and carbazole with acyl azides Eur J Org Chem 2019 1677-1684

Barman M K, Jana A and Maji B (2018) Phosphine-free NNNManganese complex catalyzed $\alpha$-alkylation of ketones with primary alcohols and friedländer quinoline synthesis Adv Synth Catal 360 3233-3238

Barman M K, Waiba S and Maji B (2018) Manganese-catalyzed direct olefination of methyl-substituted heteroarenes with primary alcohols Angew Chem Int Ed 57 9126-9130

Barsu N, Bolli S K and Sundararaju B (2017) Cobalt catalyzed carbonylation of unactivated C( $\left(\mathrm{sp}^{3}\right)-\mathrm{H}$ bonds Chem Sci 8 2431-2435

Basu A, Bhaduri S, Khwaja H, Jones P G, Karen M B and Sheldrick G M (1986) Reaction of nitrobenzene with $\left[\mathrm{M}_{3}(\mathrm{CO})_{12}\right]$ $(\mathrm{M}=\mathrm{Fe}$ or $\mathrm{Ru})$ in the presence of $\left[\mathrm{Co}_{2}(\mathrm{CO})_{8}\right]$ : isolation and structure of $\left[\mathrm{Ru}_{3}(\mathrm{CO})_{7}(\mathrm{NPh})\left(\eta^{6}-\mathrm{C}_{6} \mathrm{H}_{6}\right)\right] J$ Chem Soc Dalton Trans 2501-2503

Bayal N, Singh R and Polshettiwar V (2017) Nanostructured silica-titania hybrid using dendritic fibrous nanosilica as a photocatalyst ChemSusChem 10 2182-2191

Beesu M and Periasamy M (2011) Reactive iron carbonyl reagents via reaction of metal alkoxides with $\mathrm{Fe}(\mathrm{CO})_{5}$ or $\mathrm{Fe}_{2}(\mathrm{CO})_{9}$ : Synthesis of cyclobutenediones via double carbonylation of alkynes J Org Chem 76 543-549

Beesu M and Periasamy M (2012) Stereoselective synthesis of $\alpha, \beta$-unsaturated carboxylic acids from alkynes using the $\mathrm{Fe}(\mathrm{CO})_{5} / \mathrm{t}-\mathrm{BuOK} / \mathrm{AcOH} / \mathrm{CH}_{2} \mathrm{Cl}_{2}$ reagent system $J$ Organomet Chem 705 30-33

Bera J K, Nethaji M and Samuelson A G (1999) Anion-controlled nuclearity and metal-metal distances in copper(I)-dppm complexes (dppm ) bis(diphenylphosphino)methane) Inorg Chem 38 218-228

Bhaduri S, Gopalkrishnan K S, Sheldrick G M, Clegg W and Stalke D (1983) Reaction of triruthenium dodecacarbonvl with nitrobenzene and structure of $\mathrm{p} 3$-phenylnitrenetriruthenium decacarbonyl, $\left[\mathrm{RU}_{3}(\mathrm{CO})_{10}\left(\mathrm{~F}_{3}-\mathrm{NPh}\right)\right] J$ Chem Soc Dalton Trans 2339-2341

Bhaduri S, Lahiri G K, Mukesh D, Paul H and Sarma K (2001) Kinetic investigations on the redox reactions of platinum carbonyl clusters with dihydrogen and acid Organometallics 20 3329-3336

Bhaduri S, Mathur P, Payra P and Sharma K (1998) Coupling of catalyses by carbonyl clusters and dehydrogenases: reduction of pyruvate to L-lactate by dihydrogen $\mathrm{J} \mathrm{Am}$ Chem Soc 120 12127-12128

Bhaduri S and Mukesh D (2014) Homogeneous Catalysis: Mechanisms and industrial applications. Wiley series on catalysis

Bhaduri S, Mukhopadhyay S and Kulkarni S A (2006) Role of titanium oxidation states in polymerization activity of Ziegler-Natta catalyst: A density functional study $J$ Organomet Chem 691 2810-2820

Bharathi P and Periasamy M (1999) Metalation of iminium ions formed in the reaction of tertiary amines with $\mathrm{TiCl}_{4} \mathrm{Org}$ Lett 1 857-859

Bharathi P and Periasamy M (2000) Direct metalation of 1alkynes using $\mathrm{TiCl}_{4} / \mathrm{Et}_{3} \mathrm{~N}$ and the reactions of the 
organotitanium intermediates with electrophiles Organometallics 19 5511-5513

Bhaskar R, Sharma A K and Singh A K (2018) Palladium(II) complexes of $\mathrm{N}$-heterocyclic carbene amidates derived from chalcogenated acetamide-functionalized $1 \mathrm{H}-$ benzimidazolium salts: recyclable catalyst for regioselective arylation of imidazoles under aerobic conditions Organometallics 37 2669-2681

Bhaskararao B and Sunoj R B (2015) Origin of stereodivergence in cooperative asymmetric catalysis with simultaneous involvement of two chiral catalysts $J$ Am Chem Soc 137 $5712-15722$

Bhat I A, Avinash I and Anantharaman G (2019) Nickel(II)- and Palladium(II)-NHC complexes from hydroxypyridine functionalized C,O chelate type ligands: Synthesis, structure, and catalytic activity toward Kumada-TamaoCorriu reaction Organometallics 38 1699-1708

Bhatia B, Punniyamurthy, T and Iqbal J (1993) Cobalt(II)catalyzed reaction of aldehydes with acetic anhydride under an oxygen atmosphere: Scope and mechanism J Org Chem 58 5518-5523

Bhunia M, Hota P K, Vijaykumar G, Adhikari D and Mandal S K (2016) A highly efficient base-metal catalyst: Chemoselective reduction of imines to amines using an abnormal-NHC-Fe(0) complex Organometallics 352930 2937

Bhunia M, Vijaykumar G, Adhikari D and Mandal S K (2017) Highly active carbene potassium complexes for the ringopening polymerization of $\varepsilon$-caprolactone Inorg Chem $\mathbf{5 6}$ 14459-14466

Bhuyan M, Laskar M and Gupta B D (2008) Biphenyl-bridged dicobaloximes: synthesis, NMR, CV, and X-Ray study Organometallics 27 594-601

Biradar A V, Kotbagi T V, Dongare M K and Umbarkar S B (2008) Selective N-oxidation of aromatic amines to nitroso derivatives using a molybdenum acetylide oxo-peroxo complex as catalyst Tetrahedron Lett 49 3616-3619

Bisht R and Chattopadhyay B (2016) Formal Ir-catalyzed ligandenabled ortho and meta borylation of aromatic aldehydes via in situ-generated imines $J$ Am Chem Soc 138 84-87

Bisht R, Hoque Md E and Chattopadhyay B (2018) Amide effects in $\mathrm{C}-\mathrm{H}$ activation: noncovalent interactions with L-shaped ligand for meta borylation of aromatic amides Angew Chem Int Ed $\mathbf{5 7}$ 15762-15766

Casey C P (2005) Nobel Prize in Chemistry: Development of the olefin metathesis method in organic synthesis JChem Educ 83 192-195
Chakrabarti K, Maji M, Panja D, Paul B, Shee S, Das G K and Kundu S (2017) Utilization of $\mathrm{MeOH}$ as a $\mathrm{C} 1$ building bock in tandem three component coupling reaction $\mathrm{Org}$ Lett 19 4750-4753

Chakraborty A, Dey S, Sawoo S, Adarsh N N and Sarkar A (2010) Regioselective 1,3-dipolar cycloaddition reaction of azides with alkoxy alkynyl Fischer carbene complexes Organometallics 29 6619-6622

Chakraborty T, Sharma S, Singh H B and Butcher R J (2011) Reactions of di(o-tolyl) telluride and -selenide with palladium acetate: isolation of a novel trinuclear $\mu^{2}$-Oxo palladium complex and related trinuclear and tetranuclear palladium complexes Organometallics 30 2525-2530

Chakraborty T, Srivastava K, Singh H B and Butcher R J (2011) Palladium selenolates via oxidative addition of organylselenenyl halides to palladium(0) precursor and via cleavage reaction of diselenides: Synthesis, structure and spectroscopic investigation J Organomet Chem 696 2782-2788

Chakraborty T, Srivastava K, Singh H B and Butcher R J (2011) Selenoether ligand assisted Heck catalysis J Organomet Chem 696 2559-2564

Chakravarti R, Mano A, Iwai H, Aldeyab S S, Kumar R P, Kantam M L and Vinu A (2011) Functionalization of mesoporous carbon with superbasic $\mathrm{MgO}$ nanoparticles for the efficient synthesis of sulfonamides Chem-Eur J 17 6673-6682

Chandgude M G, Biradar A V, Kotbagi T V, Puranik V G, Dongare M K and Umbarkar S B (2012) Selective oxidation of nonrefractory and refractory sulfides by cyclopentadienyl molybdenum acetylide complexes as efficient catalysts Chem Lett 142 1352-1360

Chandra P, Pandhare S L, Umbarkar S B, Dongare M K and Vanka K (2013) Mechanistic studies on the roles of the oxidant and hydrogen bonding in determining the selectivity in alkene oxidation in the presence of molybdenum catalysts Chem-Eur J 19 2030-2040

Chandrasekhar V (2005) Inorganic and organometallic polymers, pp (108-112). Springer Berlin

Chandrasekhar V and Kumar A (2009) Assembly of diverse structural types of organotellurium compounds in the reactions of $\left(4-\mathrm{MeO}-\mathrm{C}_{6} \mathrm{H}_{4}\right)_{2} \mathrm{TeO}$ with pyridine carboxylic acids J Organomet Chem 694 2628-2635

Chandrasekhar V and Narayanan R S (2011) Organostannoxanesupported $\operatorname{Pd}(0)$ nanoparticles as efficient catalysts for Heck-coupling reactions Tetrahedron Lett 52 3527-3531

Chandrasekhar V, Gopal K and Thilagar P (2007) Nanodimensional organostannoxane molecular assemblies Acc Chem Res 40 $420-434$ 
Chandrasekhar V, Gopal K, Sasikumar P and Thirumoorthi R (2005) Organooxotin assemblies from $\mathrm{Sn}-\mathrm{C}$ bond cleavage reactions Coord Chem Rev 249 1745-1765

Chandrasekhar V, Gopal K, Singh P, Narayanan R S and Duthie A (2009) Self-assembly of organostannoxanes: Formation of gels in aromatic solvents Organometallics 28 4593-4601

Chandrasekhar V, Narayanan R S and Thilagar P (2009) Organostannoxane-supported palladium nanoparticles highly efficient catalysts for suzuki-coupling reactions Organometallics 28 5883-5888

Chatterjee B and Gunanathan C (2016) The ruthenium-catalysed selective synthesis of mono-deuterated terminal alkynes Chem Commun 52 4509-4512

Chatterjee B and Gunanathan C Ruthenium (2015) Catalyzed Selective $\alpha$ - and $\alpha, \beta$-Deuteration of alcohols using $\mathrm{D}_{2} \mathrm{O}$ Org Lett 17 4794-4797

Chatterjee B, Krishnakumar V and Gunanathan C (2016) Selective $\alpha$-Deuteration of amines and amino acids using $\mathrm{D}_{2} \mathrm{O}$ Org Lett 18 5892-5895

Chatterjee T, Dey R and Ranu B C (2014) ZnO-Supported Pd nanoparticle-catalyzed ligand-and additive-free cyanation of unactivated aryl halides using $\mathrm{K}_{4}\left[\mathrm{Fe}(\mathrm{CN})_{6}\right]$ J Org Chem 79 5875-5879

Chauvin Y (2006) 2005 Nobel Prize in Chemistry: Awarded for the development of the metathesis reaction in organic synthesis Platinum Metals Rev 50 35-37

Choudary B M, Chowdari N S, Jyothi K and Kantam M L (2002) Catalytic asymmetric dihydroxylation of olefins with reusable $\mathrm{OsO}_{4}^{2-}$ on ion-exchangers: The scope and reactivity using various cooxidants $J$ Am Chem Soc $\mathbf{1 2 4}$ 5341-5349

Choudary B M, Chowdari N S, Madhi S and Kantam M L (2001) A trifunctional catalyst for the synthesis of chiral diols Angew Chem Int Ed 40 4619-4623

Choudary B M, Kantam M L, Ranganath K V S, Mahendar K and Sreedhar B (2004) Bifunctional nanocrystalline $\mathrm{MgO}$ for chiral epoxy ketones via Claisen-Schmidt condensationasymmetric epoxidation reactions $J$ Am Chem Soc $\mathbf{1 2 6}$ 3396-3397

Choudary B M, Sridhar C, Kantam M L, Venkanna G T and Sreedhar B (2005) Design and evolution of copper apatite catalysts for n-arylation of heterocycles with chloro- and fluoroarenes J Am Chem Soc 127 9948-9949

Choudhury J, Podder S and Roy S (2005) Cooperative FriedelCrafts Catalysis in Heterobimetallic Regime: Alkylation of Aromatics by $\pi$-Activated Alcohols $\mathrm{J}$ Am Chem Soc 127 6162-6163
Chowdhury A D and Lahiri G K (2012) A generalized approach for iron catalyzed chemo- and regioselective formation of anti-Markovnikov acetals from styrene derivatives Chem Commun 48 3448-3450

Chowdhury A D, Das A, Irshad K, Shaikh M M and Lahiri G K (2011) Isomeric complexes of [RuII(trpy)(L)Cl] (trpy = 2,20:60,200-Terpyridine and HL = Quinaldic acid): Preference of isomeric structural form in catalytic chemoselective epoxidation process Inorg Chem 50 17751785

Chowdhury A D, Ray R and Lahiri G K (2012) An iron catalyzed regioselective oxidation of terminal alkenes to aldehyde. Chem Commun 48 5497-5499

Croft L (2010) Nobel Prize 2010: Prestige for palladium Nat Chem 21009

Dana S, Chowdhury D, Mandal A, Chipem F A S and Baidya M (2018) Ruthenium(II) catalysis/noncovalent interaction synergy for cross dehydrogenative coupling of arene carboxylic acids ACS Catal 8 10173-10179

Dana S, Mandal A, Sahoo H, Mallik S, Grandhi G S, Baidya M (2018) Ru(II)-Catalyzed oxidative Heck-type olefination of aromatic carboxylic acids with styrenes through carboxylate-assisted C-H bond activation Org Lett 20 716719

Das D, Mohapatra S S and Roy S (2015) Recent advances in heterobimetallic catalysis across a "transition metal-tin" motif Chem Soc Rev 44 3666-3690

Das D, Pratihar S and Roy S (2012) Heterobimetallic Pd-Sn catalysis: a suzuki, tandem ring-closing sequence toward indeno[2,1-b]thiophenes and Indeno[2,1-b]indoles Org Lett 14 4870-4873

Dash C, Shaikh M M, Butcher R J and Ghosh P (2010) A comparison between nickel and palladium precatalysts of 1,2,4-triazole based $\mathrm{N}$-heterocyclic carbenes in hydroamination of activated olefins Dalton Trans 392515 2524

Dash C, Shaikh M M, Butcher R J and Ghosh P (2010) Highly convenient regioselective intermolecular hydroamination of alkynes yielding ketimines catalyzed by gold(I) complexes of 1,2,4-triazole based $\mathrm{N}$-heterocyclic carbenes Inorg Chem 49 4972-4983

Datta S N, Kondru R K and Mathur P (1994) Molecular orbital calculations on $\mathrm{Fe}(\mathrm{CO})_{10}(\mu-\mathrm{CO})(\mu-\mathrm{Se})_{2}$ and $\mathrm{Fe}, \mathrm{Ru}($ $\mathrm{CO})_{10}(\mu-\mathrm{CO})\left(\mu^{4}-\mathrm{Se}\right)_{2}$ J Organomet Chem 470 169-171

Daw P, Petakamsetty R, Sarbajna A, Laha S, Ramapanicker R, Bera J K (2014) A highly efficient catalyst for selective oxidative scission of olefins to aldehydes: Abnormal- 
NHC-Ru(II) complex in oxidation chemistry J Am Chem Soc 136 13987-13990

Daw P, Sinha A, Rahaman S M W, Dinda S and Bera J K (2012) Bifunctional water activation for catalytic hydration of organonitriles Organometallics 31 3790-3797

De A, Zhang Q-F, Mondal B, Cheung L F, Kar S, Saha K, Varghese B, Wang L-S and Ghosh S (2018) $\left[\left(\mathrm{Cp}_{2} \mathrm{M}\right)_{2} \mathrm{~B}_{9} \mathrm{H}_{11}\right](\mathrm{M}$ $=\mathrm{Zr}$ or Hf): early transition metal 'guarded' heptaborane with strong covalent and electrostatic bonding Chem Sci 9 1976-1981

Deb A, Hazra A, Peng Q, Paton R S and Maiti D (2017) Detailed mechanistic studies on palladium-catalyzed selective $\mathrm{C}$ H olefination with aliphatic alkenes: A significant influence of proton shuttling J Am Chem Soc 139 763-775

Desai S P, Mondal M and Choudhury J (2015) Chelating bis-NHeterocyclic carbene (NHC)-Pd(II) complexes for oxidative arene $\mathrm{C}-\mathrm{H}$ functionalization Organometallics 34 2731-2736

Devarajulu S, Srinivasamurthy K and Chandrasekaran S (2007) A new selena-aza-payne-type rearrangement of aziridinylmethyl tosylates mediated by tetraselenotungstate Eur J Org Chem 2007 4543-4551

Devarajulu S, Srinivasamurthy K, Venkataraman G and Chandrasekaran S (2010) Tetrathiomolybdate mediated rearrangement of aziridinemethanol tosylates: A thia-azapayne rearrangement $J$ Org Chem 75 5533-5541

Devarajulu S, Venkataraman G and Chandrasekaran S (2007) Conformationally locked bridged bicyclic diselenides: Synthesis, structure, Se...O Interaction, and theoretical studies J Org Chem 72 5313-5319

Dey R, Mukherjee N, Ahammed S and Ranu B C (2012) Highly selective reduction of nitroarenes by iron( 0 ) nanoparticles in water Chem Commun 48 7982-7984

Dhara D, Kalita P, Mondal S, Narayanan R S, Mote K R, Huch V, Zimmer M, Yildiz CB, Scheschkewitz D, Chandrasekhar $\mathrm{V}$ and Jana A (2018) Reactivity enhancement of a diphosphene by reversible N-heterocyclic carbene coordination Chem Sci 9 4235-4243

Dinda S and Samuelson A G (2012) The nature of bond critical points in dinuclear copper (I) complexes Chem-Eur J 18 3032-3042

Dinda S, Sebastian K L and Samuelson A G (2010) Mechanistic aspects of nucleophilic substitution at half-sandwich metal complexes Organometallics 29 6209-6218

Dubey P, Gupta S and Singh A K (2018) Base free N-alkylation of anilines with $\mathrm{ArCH}_{2} \mathrm{OH}$ and transfer hydrogenation of aldehydes/ketones catalyzed by the complexes of $\eta^{5}$ -
Cp*Ir(III) with chalcogenated Schiff bases of anthracene9-carbaldehyde Dalton Trans 47 3764-3774

Dutta C, Sainaba A B and Choudhury J (2019) Annulating thiazolium cations via direct double $\mathrm{C}-\mathrm{H}$ activation strategy: Rh-N, S-Heterocyclic carbene is the key Chem Commun 55 854-857

Dutta G and Gupta B D (2011) Cobaloximes with mixed dioximes having $\mathrm{C}$ and $\mathrm{S}$ side chains: Synthesis, structure and reactivity J Organomet Chem 696 2693-2701

Dutta G, Mandal D and Gupta B D (2012) Pyrazine bridged dicobaloximes with bis(thiophenyl)glyoxime and their molecular oxygen insertion J Organomet Chem 706 30-36

Dutta I, Yadav S, Sarbajna A, De S, Holscher M, Leitner W and Bera J K (2018) Double dehydrogenation of primary amines to nitriles by a ruthenium complex featuring pyrazole functionality $J$ Am Chem Soc $1408662-8666$

Dwivedi D, Sahu V K, Mobin S M and Singh S K (2018) Cyclopentadienyl-Ru(II)-pyridylaminecomplexes: Synthesis, X-ray Structure, and application in catalytic transformation of bio-derived furans to levulinicacid and diketones in water Inorg Chem 57 4777-4787

Elias A J (2018) The chemistry of the p-block elements: Syntheses, reactions and applications. Universities Press, Hyderabad

Elias A J, Twamley B, Haist R, Oberhammer H, Henkel G, Krebs B, Lork E, Mews R and Shreeve J M (2001) Tetrameric fluorophosphazene, $\left(\mathrm{NPF}_{2}\right)_{4}$, planar or puckered $J \mathrm{Am}$ Chem Soc 123 10299-10303

Ganapathy D and Sekar G (2014) Efficient synthesis of polysubstituted olefins using stable palladium nanocatalyst: applications in synthesis of tamoxifen and isocombretastatin A4 Org Lett 16 3856-3859

Ghatak T, Sarkar M, Dinda S, Dutta I, Rahaman S M W, Bera J K (2015) Olefin oxygenation by water on an iridium center $J$ Am Chem Soc 137 6168-6171

Ghavale N, Manjare S T, Singh H B and Butcher R J (2015) $\mathrm{Bis}$ (chalcogenones) as pincer ligands: Isolation and Heck activity of the selone-ligated unsymmetrical C, C, Se-Pd pincer complex Dalton Trans 44 11893-11900

Ghorai D and Choudhury J (2014) Exploring a unique reactivity of N-Heterocyclic carbenes (NHC) in Rhodium(III)catalyzed intermolecular $\mathrm{C}-\mathrm{H}$ activation/annulation Chem Commun 50 15159-15162

Ghorai D and Choudhury J (2015) Rhodium(III)-N-Heterocyclic carbene-driven cascade $\mathrm{C}-\mathrm{H}$ activation catalysis ACS Catal $52692-2696$

Ghorai D, Dutta C and Choudhury J (2016) Switching of "rollover pathway" in rhodium(III)-catalyzed $\mathrm{C}-\mathrm{H}$ activation of 
chelating molecules ACS Catal 6 709-713

Ghosh S and Jagirdar B R (2018) A capping agent dissolution method for the synthesis of metal nanosponges and their catalytic activity towards nitroarene reduction under mild conditions Dalton Trans 47 17401-17411

Gnanakumar E S, Thushara K S, Bhange D S, Mathew R, Ajithkumar T G, Rajamohanan P R, Bhaduri S and Gopinath C S (2011) $\mathrm{MgCl}_{2} \cdot 6 \mathrm{PhCH}_{2} \mathrm{OH}-\mathrm{A}$ new molecular adduct as support material for Ziegler-Natta catalyst: Synthesis, characterization and catalytic activity Dalton Trans 40 10936-10944

Gomes H T, Selvam P, Dapurkar S E, Figueiredo J L and Faria J L (2005) Transition metal (Cu, Cr, and V) modified MCM41 for the catalytic wet air oxidation of aniline Micropor Mesopor Mat 86 287-294

Gupta B D and Kumar K (2011) Organo-bridged dicobaloximes: Synthesis, structure and nuclear magnetic resonance study Inorg Chim Acta 372 8-16

Gupta B D and Elias A J (2010 \& 2013) Basic organometallic chemistry: Concepts, syntheses and applications of transition metals. CRC Press and Universities press, Hyderabad

Gupta S K and Choudhury J (2016) A remote coordination booster enhances catalytic efficiency by accelerating the generation of active catalyst Chem Commun 52 3384-3387

Gupta S K, Sahoo S K and Choudhury J (2016) Dramatic effect of ancillary NHC ligand in the highly selective catalytic oxidative carbon-carbon multiple bond cleavage Organometallics 35 2462-2466

Hazra S, Deb M, Singh J and Elias A J (2017) Picolinamide as a directing group on metal sandwich compounds: $\mathrm{sp}^{2} \mathrm{C}-\mathrm{H}$ Bond activation and $\mathrm{sp}^{3} \mathrm{C}-\mathrm{H}$ bond oxidation Organometallics 36 1784-1794

Hoque Md E, Bisht R, Haldar C and Chattopadhyay B (2017) Noncovalent interactions in $\mathrm{Ir}$-catalyzed $\mathrm{C}-\mathrm{H}$ activation: L-shaped ligand for para-selective borylation of aromatic esters J Am Chem Soc 139 7745-7748

Hota P K, Jose A and Mandal S K (2017) Stereo- and regioselective addition of arene to alkyne using abnormal NHC based palladium catalysts: Elucidating the role of trifluoroacetic acid in Fujiwara process Organometallics 36 4422-4431

Hota P K, Sau S C and Mandal S K (2018) Metal-free catalytic formylation of amides using $\mathrm{CO}_{2}$ under ambient conditions ACS Catal 8 11999-12003

Hota P K, Vijaykumar G, Pariyar A, Sau S C, Sen T K, et al. (2015) An abnormal N-heterocyclic carbene-based palladium dimer: Aqueous oxidative heck coupling under ambient temperature Adv Synth Catal 357 3162-3170

Hotha S and Kashyap S (2006) Propargyl glycosides as stable glycosyl donors: anomeric activation and glycoside syntheses J Am Chem Soc 128 9620-9621

Iqbal J, Bhatia B and Nayyar N K (1991) Cobalt(II)acetate promoted oxidative addition of 1,3-dicarbonyl compounds to alkenes under aerobic conditions Tetrahedron 416457 4468

Iqbal J, Bhatia B and Nayyar N K (1994) Transition metalpromoted free-radical reactions in organic synthesis: The formation of carbon-carbon bonds Chem Rev 94 519-564

Jaiswal G, Landge V G, Jagadeesan D and Balaraman E (2017) Iron-based nanocatalyst for the acceptorless dehydrogenation reactions Nat Commun 82147

Jana A, Reddy C B and Maji B (2018) Manganese catalyzed á alkylation of nitriles with primary alcohols ACS Catal 8 9226-9231

Jemmis E D and Jayasree E G (2003) Analogies between Boron and Carbon Acc Chem Res 36 816-824

Jemmis E D, Balakrishnarajan M M and Pancharatna P D (2002) Electronic requirements for macropolyhedral boranes Chem Rev 102 93-144

Jindal G and Sunoj R B (2014) Importance of ligand exchanges in Pd (II)-Brønsted acid cooperative catalytic approach to spirocyclic rings $J$ Am Chem Soc 136 15998-16008

John A and Ghosh P (2010) Fascinating frontiers of N/Ofunctionalized N-heterocyclic carbene chemistry: from chemical catalysis to biomedical applications Dalton Trans 39 7183-7206

John A, Shaikh M M and Ghosh P (2009) Palladium complexes of abnormal N-heterocyclic carbenes as precatalysts for the much preferred $\mathrm{Cu}$-free and amine-free Sonogashira coupling in air in a mixed-aqueous medium Dalton Trans 47 10581-10591

Kalidindi S B and Jagirdar B R (2012) Nanocatalysis and prospects of green chemistry ChemSusChem 5 65-75

Kalidindi S B, Sanyal U and Jagirdar B R (2011) Chemical synthesis of metal nanoparticles using amine-boranes ChemSusChem 4 317-324

Kalsi D, Dutta S, Barsu N, Rueping M and Sundararaju B (2018) Room-temperature $\mathrm{C}-\mathrm{H}$ bond functionalization by merging cobalt and photoredox catalysis ACS Catal $88115-$ 8120

Kantam M L, Reddy P V, Srinivas P, Venugopal A, Bhargava S, Nishina Y (2013) Nanocrystalline magnesium oxidestabilized palladium( 0 ): the Heck reaction of heteroaryl bromides in the absence of additional ligands and base 
Catal Sci Technol 3 2550-2554

Kantam M L, Yadav J, Laha S, Srinivas P, Sreedhar B and Figueras F (2009) Asymmetric hydrosilylation of ketones catalyzed by magnetically recoverable and reusable copper ferrite nanoparticles J Org Chem 74 4608-4611

Karthik V, Bhat I A and Anantharaman G (2013) Backbone thiofunctionalized imidazol-2-ylidene-metal complexes: synthesis, structure, electronic properties, and catalytic activity Organometallics 32 7006-7013

Karthik V, Gupta V and Anantharaman G (2014) Synthesis of imidazole-based functionalized mesoionic carbene complexes of palladium: Comparison of donor properties and catalytic activity toward Suzuki-Miyaura coupling Organometallics 33 6218-6222

Karunakar G V and Periasamy M (2006) Conversion of propargyl alcohols to chloroallenes and arylalkynes using the $\mathrm{TiCl}_{4} /$ $\mathrm{R}_{3} \mathrm{~N}$ reagent system $J$ Org Chem 71 7463-7466

Katari M, Rao M N, Rajaraman G and Ghosh P (2012) Computational insight into a Gold(I) N-Heterocyclic carbene mediated alkyne hydroamination reaction Inorg Chem 51 5593-5604

Kayastha A A and Hotha S (2012) Versatile gold catalyzed transglycosidation at ambient temperature Chem Commun 48 7161-7163

Keshav K, Singh N and Elias A J (2010) Synthesis and reactions of ethynylferrocene-derived fluoro- and chlorocyclotriphosphazenes Inorg Chem 49 5753-5765

Kiran B, Anoop A and Jemmis E D (2002) Control of stability through overlap matching: Closo-carborynes and clososilaborynes J Am Chem Soc 124 4402-4407

Klose S, Florke U, Egold H and Mathur P (2003) ChalcogenCentered Spirocyclic Mixed-Metal Carbonyl Complexes: Synthesis and Molecular Structures of $(\mathrm{CO})_{8}\left(-\mathrm{PCy}_{2}\right) \mathrm{Re}_{2}$ $(4-\mathrm{E}) \mathrm{Fe}_{2}(-\mathrm{ER})(\mathrm{CO})_{6}$ and $\left[(\mathrm{CO})_{8}\left(-\mathrm{PCy}_{2}\right) \mathrm{Re}_{2}(4-\right.$ $\left.\mathrm{E}) \mathrm{Fe}_{2}(\mathrm{CO})_{6}\right]_{2}\left(4-\mathrm{E}_{2}\right)(\mathrm{E}=\mathrm{S}, \mathrm{Se}, \mathrm{Te} ; \mathrm{R}=$ Organic Residue $)$ Organometallics 22 3360-3366

Koshti V S, Mote N R, Gonnade R G and Chikkali S H (2015) Highly enantioselective Pd-catalyzed synthesis of Pstereogenic supramolecular phosphines, self-assembly, and implication Organometallics 34 4802-4805

Koshti V, Gaikwad S and Chikkali S H (2014) Contemporary avenues in catalytic $\mathrm{P}-\mathrm{H}$ bond addition reaction: A case study of hydrophosphination Coord Chem Rev 265 5273

Kotha S and Chavan A (2010) Design and synthesis of benzosultine-sulfone as a O-xylylene precursor via crossenyne metathesis and Rongalite: Further expansion to polycyclics via regioselective Diels-Alder reaction J Org Chem 75 4319-4322

Kotha S and Ghosh A K (2004) The Diels-Alder approach for the synthesis of tetralin-based $\alpha$-Amino acid derivatives and their modification by the Suzuki-Miyaura crosscoupling reaction Diels-Alder aaproach for the synthesis of tetralin-based $\alpha$-Amino acid deriviatives Synthesis 4 558-567

Kotha S and Gunta R (2017) Synthesis of intricate fused Nheterocycles via ring-rearrangement metathesis J Org Chem 82 8527-8535

Kotha S and Khedkhar P (2009) Differential reactivity pattern of hybrid o-quinodimethane precursors: Strategic expansion to annulated benzocycloalkanes via Rongalite J Org Chem 74 5667-5670

Kotha S and Mandal K (2006) Suzuki-Miyaura cross-coupling and ring-closing metathesis: A strategic combination for the synthesis of cyclophane derivatives Eur J Org Chem 2006 5387-5393

Kotha S and Mandal K (2009) A retrospective on the design and synthesis of novel molecules through a strategic consideration of metathesis and Suzuki-Miyaura crosscoupling Chem Asian J 4 354-362

Kotha S S, Chandrasekar S, Sahu S and Sekar G (2014) IronTEMPO-catalyzed domino aerobic alcohol oxidation/ oxidative cross-dehydrogenative coupling for the synthesis of $\alpha$-keto amides Eur J Org Chem 2014 7451-7457

Kotha S, Bansal D, Singh K and Banerjee S (2011) Synthesis of new fluorescent macrocyclic $\alpha$-amino acid derivatives via tandem cross-enyne/ring-closing metathesis cascade catalyzed by ruthenium based catalysts $J$ Organomet Chem 696 1856-1860

Kotha S, Lahiri K and Kashinath D (2002) Recent applications of the Suzuki-Miyaura cross-coupling, reaction in organic synthesis Tetrahedron 58 9633-9695

Kotha S, Mesharam M, Khedkar P, Benerjee S and Deodhar D (2015) Recent application of ring-rearrangement metathesis in organic synthesis Beilstein J Org Chem 11 1833-1864

Kotha S, Mishram M and Tiwari A (2009) Advanced approach to polycyclics by a synergistic combination of enyne metathesis and Diels-Alder reaction Chem Soc Rev 38 2065-2092

Kotha S, Shah V R and Mandal K (2007) Formation of arenes via diallylarenes: Strategic utilization of Suzuki-Miyaura cross-coupling, Claisen rearrangement and ring-closing metathesis Adv Synth Catal 349 1159-1172

Krishnakumar V and Gunanathan C (2018) Ruthenium-catalyzed 
selective $\alpha$-deuteration of aliphatic nitriles using $\mathrm{D}_{2} \mathrm{O}$ Chem Commun 54 8705-8708

Kumar A and Samuelson A G (2011) Diastereospecific coupling of imines by low-valent titanium: An experimental and computational study Eur J Org Chem 2011 951-959

Kumar A, Naaz A, Palanisamy P A, Panda D and Ghosh P (2018) Anticancer property studies of chiral palladium Nheterocyclic carbene complexes and process for preparation there of US20180194789A1 2018

Kumar A, Naaz A, Prakasham A P, Gangwar M K, Butcher R J, Panda D and Ghosh P (2017) Potent anticancer activity with high selectivity of a chiral palladium N-Heterocyclic carbene complex ACS Omega 2 4632-4646

Kumar A, Semwal S and Choudhury J (2019) Catalytic conversion of $\mathrm{CO}_{2}$ to formate with renewable hydrogen donors: An ambient-pressure and $\mathrm{H}_{2}$-independent strategy ACS Catal $92164-2168$

Kumar D, Deb M, Singh J, Singh N, Keshav K and Elias A J (2016) Chemistry of the highly stable hindered cobalt sandwich compound, $\left(\eta^{5}-\mathrm{Cp}\right) \mathrm{Co}\left(\eta^{4}-\mathrm{C}_{4} \mathrm{Ph}_{4}\right)$ and its derivatives Coord Chem Rev 306 115-170

Kumar D, Prakasham A P, Bheeter L P, Sortais J B, Gangwar M, Roisnel T, Kalita AC, Darcel C and Ghosh P (2014) Cationic iron(II) complexes of the mixed cyclopentadienyl $(\mathrm{Cp})$ and the N-heterocyclic carbene (NHC) ligands as effective precatalysts for the hydrosilylation of carbonyl compounds J Organomet Chem 762 81-87

Kumar D, Singh J and Elias A J (2014) Chiral multidentate oxazoline ligands based on cyclophosphazene cores: synthesis, characterization and complexation studies Dalton Trans 43 13899-13912

Kumar D, Singh N, Keshav K and Elias A J (2011) Ring-closing metathesis reactions of terminal alkene-derived cyclic phosphozenes Inorg Chem 50 250-260

Kumar K and Gupta B D (2011) Reactivity studies of aryl cobaloximes with molecular oxygen and electrophiles $J$ Organomet Chem 696 2280-2286

Kumar K and Gupta B D (2011) Reactivity studies of aryl cobaloximes with molecular oxygen and electrophiles $J$ Organomet Chem 696 2280-2286

Kumar M S, Gupta R P and Elias A J (2008) Synthesis and selectivity in the formation of cyclophosphazene-derived 1,3-cyclohexadienes from reactions of $\mathrm{RCpCo}(\mathrm{COD})[\mathrm{R}$ ) $\mathrm{MeOC}(\mathrm{O})$ ] with alkynes and alkenes Inorg Chem 473433 3441

Kumar P, Gupta R K and Pandey D S (2014) Half-sandwich ruthenium arene complexes: Synthetic strategies and relevance in catalysis Chem Soc Rev $\mathbf{4 3}$ 707-733

Kumar R, Katari M, Choudhary A, Rajaraman G and Ghosh P (2017) Computational insight into the hydroamination of an activated olefin, As catalyzed by a 1,2,4-triazole-derived Nickel(II) N-heterocyclic carbene complex Inorg Chem 56 14859-14869

Kumar S K and Singh H B (1990) Synthesis and structure of di2-benzo[ blthienyl ditelluride J Organomet Chem 397 161167

Kumarasamy E, Raghunathan R, Kandappa S K, Sreenithya A, Jockusch S, Sunoj R B and Sivaguru J (2017) Transposed Paterno-Buchi reaction J Am Chem Soc 139 655-662

Kundu A and Roy S (2000) Copper(II)/Tin(II) reagent for allylation, propargylation, alkynylation, and benzylation of diselenides: A novel bimetallic reactivity Organometallics 19 105-107

Kundu D, Chatterjee T and Ranu B C (2013) Magnetically Separable $\mathrm{CuFe}_{2} \mathrm{O}_{4}$ nanoparticles catalyzed ligand free C$\mathrm{S}$ coupling in water: access to $(E)$ and $(Z)$ styrenyl, heteroaryl and sterically hindered aryl sulfides $A d v$ Synth Catal 355 2285-2296

Layek K, Kantam M L, Shirai M, Nishio-Hamane D, Sasakid T and Maheswarana H (2012) Gold nanoparticles stabilized on nanocrystalline magnesium oxide as an active catalyst for reduction of nitroarenes in aqueous medium at room temperature Green Chem 14 3164-3174

Mahesh D, Sadhu P and Punniyamurthy T (2016) Copper(II)catalyzed oxidative cross-coupling of anilines, primary alkyl amines, and sodium azide using TBHP: A route to 2substituted benzimidazoles J Org Chem 81 3227-3234

Mahesh D, Satheesh V, Kumar S V and Punniyamurthy T (2017) Copper(II)-catalyzed oxidative coupling of anilines, methyl arenes, and $\mathrm{TMSN}_{3}$ via $\mathrm{C}\left(\mathrm{sp}^{3} / \mathrm{sp}^{2}\right)-\mathrm{H}$ functionalization and $\mathrm{C}-\mathrm{N}$ bond formation Org Lett 19 6554-6557

Maishal T K and Sarkar A(2002) An air-stable, reusable, bimetallic version of grubbs' catalyst for alkene metathesis Synlett $\mathbf{1 1}$ 1925-1927

Maji A, Dahiya A, Lu G, Bhattacharya T, Brochetta M, Zanoni G, Liu P, Maiti D (2018) H-bonded reusable template assisted paraselective ketonisation using soft electrophilic vinyl ethers Nat Commun 93582

Maji B and Barman M K (2017) Recent developments of manganese complexes for catalytic hydrogenation and dehydrogenation reactions Synthesis 49 3377-3393

Maji M, Chakrabarti K, Paul B, Roy B C and Kundu S (2018) Ruthenium(II)-NNN-pincer-complex-catalyzed reactions between various alcohols and amines for sustainable $\mathrm{C}-\mathrm{N}$ 
and C-C bond formation Adv Synth Catal $360722-729$

Maji P, Mahalakshmi L, Krishnamurthy S S and Nethaji M (2011) Cyclometalated complexes derived from calix[4]arene bisphosphites and their catalytic applications in crosscoupling reactions J Organomet Chem 696 3169-3179

Mala D, Jagirdar B R, Patil Y P and Nethaji M (2017) Homobimetallic hydride and dihydrogen complexes of ruthenium bearing $\mathrm{N}$-heterocyclic carbene ligands $J$ Organomet Chem 830 203-211

Mala D, Jagirdar B R, Patil Y P and Nethaji M (2018) Temperature-dependent elongation of the $\mathrm{H}-\mathrm{H}$ bond in dihydrogen complexes of $\mathrm{Ru}(\mathrm{II})$ bearing an NHC ligand: Effect of the NHC and trans ligands Inorg Chim Acta 483 411-424

Mamillapalli N C and Sekar G (2014) Chemoselective reduction of $\alpha$-keto amides using nickel catalysts Chem Commun $\mathbf{5 0}$ 7881-7884

Mamillapalli N C and Sekar G (2015) Chemoselective reductive deoxygenation and reduction of $\alpha$-keto amides by using a palladium catalyst Adv Synth Catal 357 3273-3283

Mamillapalli N C and Sekar G (2015) Enantioselective synthesis of $\alpha$-hydroxy amides and b-amino alcohols from a-keto amides Chem-Eur J 21 18584-8588

Mandal A, Dana S, Sahoo H, Grandhi G S and Baidya M (2017) Ruthenium(II)-catalyzed ortho-C-H chalcogenation of benzoic acids via weak O-coordination: Synthesis of chalcogenoxanthones Org Lett 19 2430-2433

Mandal D and Gupta B D (2007) Hindered rotation leading to nonequivalence in 2-substituted benzyl cobaloximes: Structure-property relationship Organometallics $\mathbf{2 6} 658$ 670

Mandal D, Bhuyan M, Laskar M and Gupta B D (2007) Co-C bond homolysis: Reactivity difference between alkyl- and benzylcobaloximes Organometallics 26 2795-2798

Mandal D, Dolai R, Kalita P, Narayanan R S, Kumar R, Sobottka S, Sarkar B, Rajaraman G, Chandrasekhar V, Jana A (2018) "Abnormal" addition of NHC to a conjugate acid of CAAC: formation of $N$-alkyl substituted CAAC Chem-Eur $J \mathbf{2 4}$ $12722-12727$

Mandal S K, Gowda G A N, Krishnamurthy S S and Nethaji M (2003) Palladium(II) allyl complexes of chiral diphosphazane ligands:ambident coordination behaviour and stereodynamic studies in solution Dalton Trans 10161027

Mandal S K, Venkatakrishnan T S, Sarkar A and Krishnamurthy S S (2006) Steric and electronic effects in stabilizing allylpalladium complexes of "P-N-P" ligands, $\mathrm{X}_{2} \mathrm{PN}(\mathrm{Me}) \mathrm{PX}_{2}$
$\left(\mathrm{X}=\mathrm{OC}_{6} \mathrm{H}_{5}\right.$ or $\left.\mathrm{OC}_{6} \mathrm{H}_{3} \mathrm{Me}_{2}-2,6\right)$ J Organomet Chem 691 2969-2977

Manikandan R, Madasamy P and Jeganmohan M (2016) Ruthenium-catalyzed ortho alkenylation of aromatics with alkenes at room temperature with hydrogen evolution $A C S$ Catal 6 230-234

Manjare S T, Singh H B and Butcher R J (2012) Synthesis and glutathione peroxidase-like activity of N-Heterocyclic carbene derived cationic diselenides Tetrahedron 68 1056110566

Mathur P and Hossain Md M (1993) Acetylenic bond reduction on $\mathrm{Fe}_{2}(\mathrm{CO})_{6}\left(\mu-\mathrm{Se}_{2}\right)$ and synthesis of the double-butterfly complex $\quad\left[\left\{(\mathrm{CO})_{6} \mathrm{Fe}_{2}(\mathrm{M}-\mathrm{Se})_{2}\right\}_{2} \mathrm{C}(\mathrm{Ph})-\mathrm{C}(\mathrm{H})\right]$ Organometálics 12 2398-2400

Mathur P, Dash A K, Hossain Md M and Satyanarayana C V V (1995) Acetylenic derivatives of $\mathrm{Fe}_{2}(\mathrm{CO})_{6}\left(\mu-\mathrm{Se}_{2}\right)$ : Synthesis and spectroscopic characterization of $\left[(\mathrm{CO})_{6} \mathrm{Fe}_{2}(\mu-\mathrm{Se} \mathrm{C}(\mathrm{H})=\mathrm{C}(\mathrm{H}) \mathrm{Se})\right]$ and $\left[\left((\mathrm{CO})_{6} \mathrm{Fe}_{2} \mathrm{Se}_{2}\right)_{2}(\mu-\right.$ $\mathrm{C}-\mathrm{H})-\mathrm{C}(\mathrm{H}))$ ] J Organomet Chem 493 257-260

Mathur P, Ghosh S, Sarkar A and Tho"ne C (1998) Annulation reactions of Fischer carbene complexes tethered on a chalcogen-stabilized iron carbonyl cluster: Dependence of reaction pathway on chalcogen atom Organometallics 17 3926-3930

Mathur P, Hossain Md M and Rashid R S (1994) Molecular structures of $\mathrm{Fe}_{4}(\mathrm{CO})_{11}(\mu-\mathrm{Se})_{2}$ and $\mathrm{Fe}_{3} \mathrm{Ru}(\mathrm{CO})_{11}(\mu-\mathrm{Se})_{2} J$ Organomet Chem 467 245-249

Mathur P, Hossain Md M and Rheingold A L (1996) Diacetylenebridged clusters: Synthesis and characterization of $(\mathrm{CO})_{6} \mathrm{Fe}_{2} \mathrm{Se}_{2}\{\mu-\mathrm{HC}=\mathrm{C}(\mathrm{Ca} \equiv \mathrm{CR})\}, \quad\left\{(\mathrm{CO})_{6} \mathrm{Fe}_{2} \mathrm{Se}_{2}\right\}_{2}\{\mu-$ $\mathrm{HC}-\mathrm{C}(\mathrm{Ca} \equiv \mathrm{CR})\} \quad(\mathrm{R}=\mathrm{Me}$ or $n-\mathrm{Bu})$ and $(\mathrm{CO})_{6} \mathrm{Fe}_{2} \mathrm{Se}_{2}(\mu-$ $\mathrm{HC}=\mathrm{CC}-\mathrm{CCH}_{3} \mathrm{OS}_{3}(\mathrm{CO})_{10} J$ Organomet Chem 507 187195

Mathur P, Hossain Md M, Umbarkar S, Satyanarayana C V V, Tavale S S, Puranik V G (1995) Addition of phenylacetylene to the mixed-chalcogenide compounds $(\mathrm{CO})_{6} \mathrm{Fe}_{2}(\mu-\mathrm{Se} \mathrm{Te})$, $(\mathrm{CO})_{6} \mathrm{Fe}_{2}(\mu-\mathrm{S} \mathrm{Se})$, and $(\mathrm{CO})_{6} \mathrm{Fe}_{2}(\mu-\mathrm{S} \mathrm{Te})$ structural characterization of $(\mathrm{CO})_{6} \mathrm{Fe}_{2}\{\mu-\mathrm{SeC}(\mathrm{H})=\mathrm{C}(\mathrm{Ph}) \mathrm{Te}]$ Organometallics 14 959-963

Mathur P, Mukhopadhyay S, Ahmed M O, Lahiri G K, Chakraborty S and Walawalkar M G (2000) Synthesis, structure, and electrochemistry of $\left[\left(\eta^{5}-\mathrm{C}_{5} \mathrm{H}_{5}\right)_{2} \mathrm{Mo}_{2}\right.$ $\left.\mathrm{WFe}_{2}(\mathrm{O})_{2}(\mathrm{~S})_{2}(\mathrm{CO})_{9}(\mathrm{CCPh})_{2}\right]$ Organometallics 195787 5790

Mathur P, Mukhopadhyay S, Lahiri G K, Chakraborty S and Thone C (2002) Synthesis, structure, and electrochemistry of acetylide and oxo incorporated mixed Fe/Mo and Fe/W chalcogen-bridged clusters Organometallics 21 5209-5215 
Mehrotra R C (2000) Organometallic chemistry: A unified approach. New age international publishers LTD, New Delhi

Midya S P, Sahoo M K, Landge V G, Rajamohanan P R and Balaraman E (2015) Reversed reactivity of anilines with alkynes in the rhodium-catalysed $\mathrm{C}-\mathrm{H}$ activation/ carbonylation tandem Nat Commun 68591

Mitra R and Samuelson A G (2014) Substitution-modulated anticancer activity of half- sandwich ruthenium(II) complexes with heterocyclic ancillary ligands Eur J Inorg Chem 2014 3536-3546

Mitra R, Das S, Shinde S V, Sinha S, Somasundaram K and Samuelson A G (2012) Anticancer activity of hydrogenbond-stabilized half-sandwich $\mathrm{Ru}(\mathrm{II})$ complexes with heterocycles Chem-Eur J 18 12278-12291

Modak S, Gangwar M K, Rao M N, Madasu M, Kalita A C, Dorcet V, Shejale M A, Butcher, R J and Ghosh P (2015) Fluoride-free Hiyama coupling by palladium abnormal Nheterocyclic carbene complexes Dalton Trans 4417617. 17628

Mohapatra S K, Sonavane S U, Jayaram R V and Selvam P (2002) Regio- and chemoselective catalytic transfer hydrogenation of aromatic nitro and carbonyl as well as reductive cleavage of azo compounds over novel mesoporous NiMCM-41 molecular sieves Org Lett 24 $4297-4300$

Mondal B, Bag R, Ghorai S, Bakthavachalam K, Jemmis E D and Ghosh S (2018) Synthesis, structure, bonding, and reactivity of metal complexes comprising diborane(4) and diborene(2): $\left[\left\{\mathrm{Cp} * \mathrm{Mo}(\mathrm{CO})_{2}\right\}_{2}\left\{\mu-\eta^{2}: \eta^{2}-\mathrm{B}_{2} \mathrm{H}_{4}\right\}\right]$ and $\left[\left\{\mathrm{Cp} * \mathrm{M}(\mathrm{CO})_{2}\right\}_{2} \mathrm{~B}_{2} \mathrm{H}_{2} \mathrm{M}(\mathrm{CO})_{4}\right], \mathrm{M}=\mathrm{Mo}, \mathrm{W}$ Angew Chem Int Ed 57 8079-8083

Mote N R, Patel K, Shinde D R, Gaikwad S R. Koshti V S, Gonnade R G and Chikkali S H (2017) H-Bonding assisted self-assembly of anionic and neutral ligand on metal: A comprehensive strategy to mimic ditopic ligands in olefin polymerization Inorg Chem 56 12448-12456

Muthukumar A and Sekar G (2017) Zinc-catalyzed chemoselective alkylation of $\alpha$-keto amides with 2-alkylazaarenes $\mathrm{Org}$ Biomol Chem 15 691-700

Muthukumar A, Sangeetha S and Sekar G (2018) Recent developments in functionalization of acyclic $\alpha$-keto amides Org Biomol Chem 16 7068-7083

Nagaraja C M, Parameswaran P, Jemmis E D and Jagirdar B R (2007) Heterolytic activation of $\mathrm{H}-\mathrm{X}(\mathrm{X}) \mathrm{H}, \mathrm{Si}, \mathrm{B}$, and C) bonds: An experimental and theoretical investigation $\mathrm{J} \mathrm{Am}$ Chem Soc 129 5587-5596

Nagendrappa G and Kumar Y C S (2011) The 2010 Chemistry
Nobel Prize: $\operatorname{Pd}(0)$-Catalyzed organic synthesis Resonance 2011 152-164

Nandakumar A, Midya S P, Landge V G and Balaraman E (2015) Transition-metal-catalyzed hydrogen-transfer annulations: access to heterocyclic scaffolds Angew Chem Int Ed 54 11022-11034

Nandi M, Sathe K M and Sarkar A(1992) Unusual rearrangement of Fischer carbene complexes to ketones JChem Soc Chem Commun 1992 793-794

Nguyen D L, Gillot S, Souza D O, Blanchard P, Lamonier C, Berrier E, Kotbagi T V, Dongare M K, Umbarkar S B, Cristol S, Payen E and Lancelot C (2012) One-pot sol-gel preparation for efficient cobalt-molybdenum- $\mathrm{TiO}_{2}$ hydrotreating catalysts ChemCatChem 4 2112-2120

Panda A, Menon S C, Singh H B and Butcher R J (2001) Synthesis of some macrocycles: Bicycles from bis(o-formylphenyl) selenide: X-ray crystal structure of bis(o-formylphenyl) selenide and the first 28-membered selenium containing macrocyclic ligand J Organomet Chem 623 87-94

Pandey S and Chikkali S H (2015) Highly regioselective isomerizing hydroformylation of long-chain internal olefins catalyzed by a rhodium bis(Phosphite) complex ChemCatChem 7 3468-3471

Pandey S, Raj K V, Shinde D R, Vanka K, Kashyap V, Kurungot S, Vinod C P and Chikkali S H (2018) Iron catalyzed hydroformylation of alkenes under mild conditions: evidence of an $\mathrm{Fe}(\mathrm{II})$ catalyzed process $\mathrm{J}$ Am Chem Soc $1404430-4439$

Panja S, Ahammed S and Ranu B C (2017) Highly chemoselective reduction of azides to amines by $\mathrm{Fe}(0)$ nanoparticles in water at room temperature Tetrahedron Lett 58 3457-3460

Panja S, Maity P, Kundu D and Ranu B C (2017) Iron (0) nanoparticles mediated direct conversion of aryl/heteroaryl amines to chalcogenides via in situ diazotization Tetrahedron Lett 58 3441-3445

Paul B, Shee S, Panja D, Chakrabarti K and Kundu S (2018) Direct synthesis of N,N-Dimethylated and $\beta$-Methyl N,Ndimethylated amines from nitriles using methanol: Experimental and computational studies ACS Catal $82890-$ 2896

Paul H, Bhaduri S and Lahiri G K (2003) Platinum carbonyl cluster derived catalyst of superior activity in ketone and unusual selectivity in nitrile hydrogenation reactions Organometallics 22 3019-3021

Periasamy M (2002) New synthetic methods using the $\mathrm{TiCl}_{4}{ }^{-}$ $\mathrm{NR}_{3}$ reagent system ARKIVOC 2002 151-166

Periasamy M, Beesu M and Raj D S (2008) A simple and 
convenient method for the synthesis of cyclobutenediones from alkynes using new $\mathrm{Fe}(\mathrm{CO})_{5} / \mathrm{NaH} / \mathrm{MeI}$ reagent system J Organomet Chem 693 2843-2846

Periasamy M, Ganesan S S and Suresh S (2010) $\mathrm{TiCl}_{4}$ promoted menthyl ester chiral auxiliary mediated synthesis of chiral syn- $\alpha$-amino esters and applications of a representative syn- $\alpha$-amino ester Tetrahedron: Asymmetry 21 385-392

Periasamy M, Mukkanti A and Raj D S (2004) Synthesis of cyclobutenediones and anhydrides from alkynes using the $\mathrm{Fe}(\mathrm{CO})_{5} / \mathrm{Me}_{3} \mathrm{NO}$ Reagent System Organometallics $\mathbf{2 3}$ 6323-6326

Podder S, Choudhury J and Roy S (2007) Secondary Benzylation with Benzyl Alcohols Catalyzed by A High-Valent Heterobimetallic Ir-Sn Complex J Org Chem 72 31293132

Podder S, Choudhury J, Roy U K and Roy S (2007) Dual-Reagent Catalysis within Ir-Sn Domain: Highly Selective Alkylation of Arenes and Heteroarenes with Aromatic Aldehydes $J$ Org Chem 72 3100-3103

Polshettiwar V, Cha D, Zhang X and Basset J M (2010) Highsurface-area silica nanospheres (KCC-1) with a fibrous morphology Angew Chem Int Ed 49 9652-9656

Polshettiwar V, Luque R, Fihri A, Zhu H, Bouhrara M and Basset J-M (2011) Magnetically recoverable nanocatalysts Chem Rev 111 3036-3075

Polshettiwara V, Lenb C and Fihri A (2009) Silica-supported palladium: Sustainable catalysts for cross-coupling reactions Coord Chem Rev 253 2599-2626

Prakash O, Sharma K N, Joshi H, Gupta P L and Singh A K (2013) Half sandwich complexes of chalcogenated pyridine based bi-(N, S/Se) and terdentate $(\mathrm{N}, \mathrm{S} / \mathrm{Se}, \mathrm{N})$ ligands with ( $\eta^{6}$-benzene)ruthenium(II): synthesis, structure and catalysis of transfer hydrogenation of ketones and oxidation of alcohols Dalton Trans 42 8736-8747

Prakasham A P, Gangwar M K and Ghosh P (2018) Michael addition of cyclic $\beta$-oxo ester and $\alpha$-methyl cyano ester substrates with activated olefins by iron complexes of benzimidazole derived N-heterocyclic carbene ligands $J$ Organomet Chem 859 106-116

Punniyamurthy T, Bhatia B and Iqbal J (1993) Cobalt(II) catalysed epoxidation of unfunctionalised alkenes with in situ generated hydroperoxide from methyl-2oxocyclopentane carboxylate and molecular oxygen Tetrahedron Lett. 34 4657-4658

Ramaraj A, Jagirdar B R and Nethaji M (2016) Small molecule binding and activation on a cationic ruthenium center of a pincer complex J Organomet Chem 825 114-124
Ramasamy B and Ghosh P (2016) The developing concept of bifunctional catalysis with transition metal N-heterocyclic carbene complexes Eur J Inorg Chem 10 1448-1465

Ramasamy B, Gangwar M K and Ghosh P (2017) Chiral oxazolidine-fused N-Heterocyclic carbene complexes of rhodium and iridium and their utility in the asymmetric transfer hydrogenation of ketones Eur J Inorg Chem 26 3253-3268

Ramesh B and Jeganmohan M (2017) Ruthenium-catalyzed remote $\mathrm{C}-\mathrm{H}$ sulfonylation of $\mathrm{N}$-aryl-2-aminopyridines with aromatic sulfonyl chlorides Org Lett 19 6000-6003

Rao M L N, Banerjee D and Giri S (2010) Palladium catalyzed cross-couplings of allylic carbonates with triarylbismuths as multi-coupling atom-efficient organometallic nucleophiles J Organomet Chem 695 1518-1525

Rao M L N, Jadhav D N and Dasgupta P (2010) Pd-catalyzed domino synthesis of internal alkynes using triarylbismuths as multicoupling organometallic nucleophiles Org Lett 12 2048-2051

Rao M L N, Venkatesh V and Jadhav D N (2008) A palladium catalyzed atom-efficient cross-coupling reactivity of triarylbismuths with $\alpha, \beta$-unsaturated acyl chlorides $J$ Organomet Chem 693 2494-2498

Rao M N, Haridas M, Gangwar M K, Rajakannu P, Kalita A C, et al. (2015) Asymmetric base-free michael addition at room temperature with nickel-based bifunctional amidofunctionalized N-heterocyclic carbene catalysts Eur J Inorg Chem 9 1604-1615

Ray L, Katiyar V, Raihan M J, Nanavati H, Shaikh M M, Ghosh P (2006) First example of a gold(I) N-heterocyclic-carbenebased initiator for the bulk ring-opening polymerization of L-lactide Eur J Inorg Chem 18 3724-3730

Ray L, Shaikh M M and Ghosh P (2007) Palladium(II) and gold(I) complexes of a new O-functionalized N-heterocyclic carbene ligand: Synthesis, structures, and catalytic application Organometallics 26 958-964

Ray R, Chowdhury A D and Lahiri G K (2013) Efficient ironcatalyzed acetal formation from styrene derivatives ChemCatChem 5 2158-2161

Ray R, Hazari A S, Chandra S, Maiti D and Lahiri G K (2018) Highly selective ruthenium-catalyzed direct oxygenation of amines to amides Chem-Eur J 24 1067-1071

Ray R, Jana R D, Bhadra M, Maiti D and Lahiri G K (2014) Efficient and simple approaches towards direct oxidative esterification of alcohols Chem-Eur J 20 15618-15624

Ray S, Mohan R, Singh J K, Samantaray M K, Shaikh M M, Panda D and Ghosh P (2007) Anticancer and antimicrobial 
metallopharmaceutical agents based on palladium, gold, and silver N-heterocyclic carbene complexes $J$ Am Chem Soc 129 15042-15053

Ray S, Shaikh M M and Ghosh P (2009) Nickel complexes of N/ $\mathrm{O}$-functionalized N-Heterocyclic carbenes as precatalysts for Michael reactions in air at room temperature under the much preferred base-free conditions Eur J Inorg Chem 13 1932-1941

Reddi Y, Tsai C, Avila C M, Toste F D and Sunoj R B (2019) Harnessing noncovalent interactions in dual-catalytic enantioselective Heck-Matsuda arylation J Am Chem Soc 141 998-1009

Reddy A C S, Choutipalli V S K, Ghorai J, Subramanian V and Anbarasan P (2017) Stereoselective palladium-catalyzed synthesis of indolines via intramolecular trapping of $\mathrm{N}$ Ylides with alkenes ACS Catal 7 6283-6288

Reddy M C and Jeganmohan M (2017) Total synthesis of aristolactam alkaloids via synergistic $\mathrm{C}-\mathrm{H}$ bond activation and dehydro- Diels-Alder reactions Chem Sci 8 41304135

Reddy V S, Krishnamurthy S S and Nethaji M (1992) Organometallics of diphosphazanes V The different coordination behavior of cis- and transcyclodiphosphazanes towards Group 6 metal carbonyl moieties J Organomet Chem 438 99-115

Roy S, Rosenthal U and Jemmis E D (2014) Metallacyclocumulenes: A theoretical perspective on the structure, bonding, and reactivity Acc Chem Res 472917 2930

Roy U K and Roy S (2010) Making and breaking of Sn-C and In-

C Bonds in situ: the cases of allyltins and allylindiums Chem Rev 110 2472-2535

Saha A and Ranu B C (2008) Highly chemoselective reduction of aromatic nitro compounds by copper nanoparticles/ ammonium formate $\mathrm{J}$ Org Chem 73 6867-6870

Saha B, Rahaman S M W, Daw P, Sengupta G and Bera J K (2014) Metal-ligand cooperation on a diruthenium platform: selective imine formation through acceptorless dehydrogenative coupling of alcohols with amines ChemEur J 20 6542-6551

Saha D, Adak L and Ranu B C (2010) Palladium(0) nanoparticlescatalyzed ligand-free direct arylation of benzothiazole via C-H bond functionalization Tetrahedron Lett 51 56245627

Saha K, Ramalakshmi R, Gomosta S, Pathak K, Dorcet V, Roisnel T, Halet J, Ghosh S (2017) Design, synthesis, and chemistry of bis(s)borate and agostic complexes of group 7 metals Chem-Eur J 23 9812-9820
Sahoo M K, Midya S P, Landge V G and Balaraman E (2017) A unified strategy for silver-, base-, and oxidant free, direct arylation of C-H bonds Green Chem 19 2111-2117

Sahoo M K, Saravanakumar K, Jaiswal G and Balaraman E (2018) Photocatalysis enabling acceptorless dehydrogenation of diaryl hydrazines at room temperature ACS Catal 87727 7733

Saleem F, Rao G K, Kumar A, Mukherjee G and Singh A K (2013) Half-Sandwich Ruthenium(II) Complexes of click generated 1,2,3- triazole based organosulfur/-selenium ligands: structural and donor site dependent catalytic oxidation and transfer hydrogenation aspects Organometallics 32 3595-3603

Samanta D, Sawoo S and Sarkar A (2006) In situ generation of gold nanoparticles on a protein surface: Fischer carbene complex as reducing agent Chem Commun 2006 34383440

Samanta D, Sawoo S, Patra S, Ray M, Salmain M and Sarkar A (2005) Synthesis of hydrophilic Fischer carbene complexes as organometallic marker and PEGylating agent for proteins J Organomet Chem 690 5581-5590

Samantaray M K, Katiyar V, Roy D, Pang K, Nanavati H, Stephen R, Sunoj R B and Ghosh P (2006) A cationic (NHeterocyclic carbene)silver complex as catalyst for bulk ring-opening polymerization of (L)-lactides Eur J Inorg Chem 15 2975-2984

Samantaray M K, Shaikh M M and Ghosh P (2009) Rare (NHC)(2)Ni-OH -Type Terminal Nickel Hydroxo and (NHC)(2)Ni-type complexes of N/O-functionalized Nheterocyclic carbenes as precatalysts for highly desirable base-free Michael reactions in air at ambient temperature Organometallics 28 2267-2275

Sanyal U and Jagirdar B R (2012) Metal and alloy nanoparticles by amine-borane reduction of metal salts by solid-phase synthesis: Atom economy and green process Inorg Chem 51 13023-13033

Sarbajna A, Dutta I, Daw P, Dinda S, Rahaman S M W, Sarkar A and Bera J K (2017) Catalytic conversion of alcohols to carboxylic acid salts and hydrogen with alkaline water ACS Catal 7 2786-2790

Sathe K M, Nandi M, Amin S R, Puranik V G and Sarkar A (1996) Rearrangement of Fischer carbene complexes to ketones: Stereochemistry and mechanism Organometallics 15 2883-2889

Satheesh V, Kumar S V and Punniyamurthy T (2018) Expedient stereospecific Co-catalyzed tandem $\mathrm{C}-\mathrm{N}$ and $\mathrm{C}-\mathrm{O}$ bond formation of N-methylanilines with styrene oxides Chem Commun 54 11813-11816 
Sau S C, Bhattacharjee R, Hota P K, Vardhanapu P K, Vijaykumar G, Govindarajan R, Datta A and Mandal S K (2019) Transforming atmospheric $\mathrm{CO}_{2}$ into alternative fuels: A metal-free approach under ambient conditions $\mathrm{Chem} \mathrm{Sci}$ 10 1879-1884

Sau S C, Bhattacharjee R, Vardhanapu P K, Vijaykumar G, Datta A and Mandal S K (2016) Metal free reduction of $\mathrm{CO}_{2}$ to methoxyborane under ambient conditions through borondiformate formation Angew Chem Int Ed 5515147 15151

Sau S C, Roy S R, Sen T K, Mullangi D and Mandal S K (2013) An Abnormal N Heterocyclic Carbene-Copper(I) Complex in Click Chemistry Adv Synth Catal 355 2982-2991

Sau S C, Santra S, Sen T K, Mandal S K and Koley D (2012) Abnormal N-heterocyclic carbene palladium complex: Living catalyst for activation of aryl chlorides in SuzukiMiyaura cross-coupling Chem Commun 48 555-557

Savitha G, Saha R and Sekar G (2016) Bimetallic chiral nanoparticles as catalysts for asymmetric synthesis article Tetrahedron Lett 57 5168-5178

Savitha G, Saha R and Sekar G (2016) Bimetallic chiral nanoparticles as catalysts for asymmetric synthesis Tetrahedron Lett 57 5168-5178

Selvam P, Krishna V and Ravat V M (2011) Selective oxidation of alkenes over uranyl-anchored mesoporous MCM-41 molecular sieves J Phys Chem C 115 1922-1931

Semwal S and Choudhury J (2016) Molecular coordination-switch in a new role: controlling highly selective catalytic hydrogenation with switchability function ACS Catal 6 2424-2428

Semwal S and Choudhury J (2017) Switch in catalyst state: single bifunctional bi-state catalyst for two different reactions Angew Chem Int Ed 56 5556-5560

Semwal S, Ghorai D and Choudhury J (2014) Wingtip-dictated cyclometalation of N-Heterocyclic carbene (NHC) ligand framework and its implication toward tunable catalytic activity Organometallics $\mathbf{3 3} 7118-7124$

Semwal S, Kumar A and Choudhury J (2018) Iridium-NHCbased catalyst for ambient pressure storage and lowtemperature release of $\mathrm{H}_{2}$ via the $\mathrm{CO}_{2} / \mathrm{HCO}_{2} \mathrm{H}$ Couple Catal Sci Technol 8 6137-6142

Semwal S, Mukkatt I, Thenarukandiyil R and Choudhury J (2017) Small 'Yaw', Large 'Bite' and electron-rich metal: revealing a stereoelectronic synergy to enhance hydride transfer activity Chem-Eur J 23 13051-13057

Sen M, Emayavaramban B, Barsu N, Premkumar J R and Sundararaju B (2016) $\mathrm{Cp} * \mathrm{Co}(\mathrm{III})$-catalyzed $\mathrm{C}\left(\mathrm{sp}^{3}\right)-\mathrm{H}$ bond activation: A highly stereoselective and regioselective alkenylation of 8 methylquinoline with alkynes $A C S$ Catal 6 2792-2796

Sen T K, Sau S C, Mukherjee A, Hota P K, Mandal S K, Maity B and Koley D (2013) Abnormal N-heterocyclic carbene main group organometallic chemistry: A debut to the homogeneous catalysis Dalton Trans 42 14253-14260

Sengoden M and Punniyamurthy T (2013) On Water: Efficient iron-catalyzed cycloaddition of aziridines with heterocumulenes Angew Chem Int Ed 52 572-575

Sengoden M, Bhowmick A and Punniyamurthy T (2017) Stereospecific copper-catalyzed domino ring opening and $\mathrm{sp}^{3} \mathrm{C}-\mathrm{H}$ functionalization of activated aziridines with nalkylanilines Org Lett 19 158-161

Sharma N, Saha R, Parveen N and Sekar G (2017) Palladiumnanoparticles-catalyzed oxidative annulation of benzamides with alkynes for the synthesis of isoquinolones Adv Synth Catal 359 1947-1958

Shee S, Ganguli K, Jana K and Kundu S (2018) Cobalt complex catalyzed atom-economical synthesis of quinoxaline, quinoline and 2-alkylaminoquinoline derivatives Chem Commun 54 6883-6886

Shimada S and Rao M L N (2012) Transition-metal catalyzed C$\mathrm{C}$ bond formation using organobismuth compounds Top Curr Chem 311 199-228

Singh A K, Pandey D S, Xu Q and Braunstein P (2014) Recent advances in supramolecular and biological aspects of areneruthenium(II) complexes Coord Chem Rev 270 3156

Singh B and Polshettiwar V (2009) Solution-phase synthesis of two-dimensional silica nanosheets using soft templates and their applications in $\mathrm{CO}_{2}$ capture Nanoscale $115365-$ 5376

Singh J, Deb M and Elias A J (2015) Palladacycles based on 8aminoquinoline carboxamides of cobalt and iron sandwich compounds and a new method to $\alpha$-alkylate $\mathrm{Cp}$ rings of metal sandwich carboxamides Organometallics 34 49464951

Singh J, Ghosh S, Deb M and Elias A J (2016) Reactions of $\mathrm{Cp}_{2} \mathrm{TiMe}_{2}$ with ferrocene and $\left(\eta^{5}-\mathrm{Cp}\right) \mathrm{Co}\left(\eta^{4}-\mathrm{C}_{4} \mathrm{Ph}_{4}\right)$ derived esters and amides: A new route for 1-methylvinyl and methyl ketone derived metal sandwich compounds $J$ Organomet Chem 818 85-91

Singh J, Kumar D, Singh N and Elias A J (2014) New chiral palladacycles from an unprecedented cyclopalladation of cyclobutadiene-bound phenyl groups of cobalt sandwich compounds Organometallics 33 1044-1052

Singh K, Sarbajna A, Dutta I, Pandey P and Bera J K (2017) Hemilability-driven water activation: a Ni(II) catalyst for 
base-free hydration of nitriles to amides Chem-Eur $J \mathbf{2 3}$ 7761-7771

Singh N and Elias A J (2011) Palladacycles of novel bisoxazoline chelating ligands based on the dimeric cyclobutadiene linked cobalt sandwich compound $\left[\left(\eta^{5}-\mathrm{Cp}\right) \mathrm{Co}\left(\eta^{4}-\mathrm{C}_{4} \mathrm{Ph}_{3}\right)\right]_{2}$ Dalton Trans $404882-4891$

Smith III M R, Bisht R, Haldar C, Pandey G, Ghaffari B, Dannatt J E, Maleczka R E, Chattopadhyay B (2018) Achieving high ortho selectivity in aniline $\mathrm{C}-\mathrm{H}$ borylations by modifying boron substituents ACS Catal 8 6216-6223

Sonavane S U, Mohapatra S K, Jayaram R V and Selvam P (2003) Catalytic transfer hydrogenation of nitro and carbonyl compounds over novel Fe(III) substituted hexagonal mesoporous aluminophosphates Chem Lett 32 $142-143$

Sreejyothi P, Sau S C, Vardhanapu P K and Mandal S K (2018) Halo-bridged abnormal NHC palladium(II) dimer for catalytic dehydrogenative cross-coupling reactions of heteroarenes J Org Chem 83 9403-9411

Suresh K D, Koutha S M and Chandrasekaran S (2005) Chemistry of tetrathiomolybdate: aziridine ring opening reactions and facile synthesis of interesting sulfur heterocycles $\mathrm{J} \mathrm{Am}$ Chem Soc 127 12760-12761

Sureshkumar D, Gopinath P and Chandrasekaran S (2012) Tetraethylammonium tetraselenotungstate: a versatile selenium transfer reagent in organic synthesis Chimia (Aarau). 66 921-929

Sureshkumar G and Hotha S (2008) Gold mediated glycosylations: selective activation of propargyl 1,2-orthoesters in the presence of aglycones containing a propargyl moiety Chem Commun 2008 4282-4284

Surya S K, Sharma N and Sekar G (2016) An efficient, stable and reusable palladium nanocatalyst: Chemoselective reduction of aldehydes with molecular hydrogen in water $A d v$ Synth Catal 358 1694-1698

Talukdar K, Roy S, Bag R and Punniyamurthy T (2019) RhCatalyzed tandem $\mathrm{C}-\mathrm{C} / \mathrm{C}-\mathrm{N}$ bond formation of quinoxalines with alkynes leading to heterocyclic ammonium salts Org Biomol Chem 17 2148-2152

Thadke S A, Mishra B and Hotha S (2013) Gold(III)-catalyzed glycosidations for 1,2-trans and 1,2-cis furanosides $\mathrm{Org}$ Lett 15 2466-2469

Thakur A, Vardhanapu P K, Vijaykumar G, Hota P K and Mandal S K (2016) Abnormal N Heterocyclic carbene mediated fixation of $\mathrm{CO}_{2}$ and $\mathrm{N}_{2} \mathrm{O}$, and the activation of tetrahydro-furan and tetrahydrothiophene under ambient conditions Eur J Inorg Chem 2016 913-920
Thenarukandiyil R and Choudhury J (2015) Rhodium(III)Catalyzed activation and functionalization of pyridine $\mathrm{C}-$ $\mathrm{H}$ bond by exploring a unique double-role of ' $\mathrm{N}$ Heterocyclic carbene-pyridyl' ligand platform Organometallics 34 1890-1897

Thenarukandiyil R, Gupta S K and Choudhury J (2016) Unraveling the competition of two $\mathrm{C}-\mathrm{H}$ and two $\mathrm{M}-\mathrm{C}$ bonds in guiding the mechanism of Rhodium(III)-catalyzed $\mathrm{C}-\mathrm{H}$ activationannulation ACS Catal 6 5132-5137

Thenarukandiyil R, Thrikkykkal H and Choudhury J (2016) Rhodium(III)-catalyzed non-aromatic $\mathrm{sp}^{2} \mathrm{C} \mathrm{H}$ activation/ Annulation using $\mathrm{NHC}$ as a directing and functionalizable group Organometallics 35 3007-3013

Thiyagarajan S and Gunanathan C (2019) Catalytic cross-coupling of secondary alcohols J Am Chem Soc 141 3822-3827

Thushara K S, Gnanakumar E S, Mathew R, Ajithkumar T G, Rajamohanan P R, Bhaduri S and Gopinath C S (2012) $\mathrm{MgCl}_{2} \cdot 4\left(\left(\mathrm{CH}_{3}\right)_{2} \mathrm{CHCH}_{2} \mathrm{OH}\right)$ : A new molecular adduct for the preparation of $\mathrm{TiClx} / \mathrm{MgCl}_{2}$ catalyst for olefin polymerization Dalton Trans 41 11311-11318

Venkatakrishnan T S, Mandal S K, Kannan R, Krishnamurthy S S and Nethaji M (2007) Ruthenium hydride complexes of chiral and achiral diphosphazane ligands and asymmetric transfer hydrogenation reactions J Organomet Chem 692 1875-1891

Venkatakrishnan T S, Nethaji M and Krishnamurthy S S (2006) Ruthenium carbonyl clusters derived from pyrazolyl substituted diphosphazanes: Crystal and molecular structure of a triruthenium cluster featuring a triply bridging $\mu_{3}-\eta^{1}: \eta^{1}: \eta^{1}$ coordination mode of pyrazolate moiety $J$ Organomet Chem 691 224-228

Vidadala S R, Gayatri G, Sastry G N and Hotha S (2011) Propargyl/ methyl furanosides as potential glycosyl donors Chem Commun 47 9906-9908

Vijaykumar G, Jose A, Vardhanapu P K, Sreejyothi P and Mandal S K (2017) Abnormal-NHC-supported nickel catalysts for hydroheteroarylation of vinylarenes Organometallics 36 4753-4758

Yadagiri D and Anbarasan P (2015) Tandem 1,2-sulfur migration and (aza)-Diels-Alder reaction of b-thio-a-diazoimines: rhodium catalyzed synthesis of (fused)-polyhydropyridines, and cyclohexenes Chem Sci 6 5847-5852.

Yadagiri D, Reddy A C S and Anbarasan P (2016) Rhodium catalyzed diastereoselective synthesis of 2,2,3,3tetrasubstituted indolines from $\mathrm{N}$-sulfonyl1,2,3-triazoles and ortho-vinylanilines Chem Sci 7 5934-5938. 